\title{
Non-tuberculous mycobacterial pulmonary disease
}

\author{
Steven Cowman ${ }^{1,2}$, Jakko van Ingen $\mathbb{1}^{3}$, David E. Griffith ${ }^{4}$ and \\ Michael R. Loebinger ${ }^{1,2}$
}

Affiliations: ${ }^{1}$ Host Defence Unit, Royal Brompton Hospital, London, UK. ${ }^{2}$ Imperial College, London, UK. ${ }^{3}$ Dept of Medical Microbiology, Radboud University Medical Center, Nijmegen, The Netherlands. ${ }^{4}$ Dept of Medicine, The University of Texas Health Science Center at Tyler, Tyler, TX, United States.

Correspondence: Michael R. Loebinger, Royal Brompton Hospital, London SW3 6NP, UK.

E-mail: m.loebingerarbht.nhs.uk

@ERSpublications

Despite significant advances the management of nontuberculous mycobacterial pulmonary disease remains challenging; new approaches are needed http://bit.ly/2WPDU8V

Cite this article as: Cowman S, van Ingen J, Griffith DE, et al. Non-tuberculous mycobacterial pulmonary disease. Eur Respir J 2019; 54: 1900250 [https://doi.org/10.1183/13993003.00250-2019].

ABSTRACT Nontuberculous mycobacterial pulmonary disease (NTM-PD) is a challenging infection which is becoming increasingly prevalent, particularly in the elderly, for reasons which are unknown. While underlying lung disease is a well-established risk factor for NTM-PD, it may also occur in apparently healthy individuals. No single common genetic or immunological defect has been identified in this group, and it is likely that multiple pathways contribute towards host susceptibility to NTM-PD which further interact with environmental and microbiological factors leading to the development of disease.

The diagnosis of NTM-PD relies on the integration of clinical, radiological and microbiological results. The clinical course of NTM-PD is heterogeneous, with some patients remaining stable without the need for treatment and others developing refractory disease associated with considerable mortality and morbidity. Treatment regimens are based on the identity of the isolated species, drug sensitivity testing (for some agents) and the severity of disease. Multiple antibiotics are typically required for prolonged periods of time and treatment is frequently poorly tolerated. Surgery may be beneficial in selected cases. In some circumstances cure may not be attainable and there is a pressing need for better regimens to treat refractory and drug-resistant NTM-PD.

This review summarises current knowledge on the epidemiology, aetiology and diagnosis of NTM-PD and discusses the treatment of two of the most clinically significant species, the $M$. avium and M. abscessus complexes, with a focus on refractory disease and novel therapies. 


\section{Introduction}

The term "nontuberculous mycobacteria" (NTM) refers to members of the genus Mycobacterium which are not part of the $M$. tuberculosis complex, and conventionally also excludes M. leprae [1]. They are ubiquitous organisms found in the environment worldwide and owing to their thick lipid-rich cell wall show resistance to extremes of heat and $\mathrm{pH}$, and to many disinfectants and antibiotics [2]. They have been known to cause disease in humans for over 70 years [3] and, while they may cause infection in any bodily site, pulmonary disease (NTM-PD) is the most common manifestation in the immunocompetent [4] and will form the basis for this review.

While over 180 species have been described to date, only a small number have been reported to cause disease in humans [5]. NTM can be divided into rapidly growing mycobacteria, which may form colonies within 7 days, of which the $M$. abscessus complex, M. chelonae and M. fortuitum are the most clinically relevant; and slow growing mycobacteria, which may take up to 12 weeks to grow, of which the M. avium complex (MAC), M. xenopi, M. kansasii, M. simiae, M. malmoense and M. szulgai are the most important [6-8]. This phenotypic division remains clinically relevant, as important differences in management exists between the two groups [8].

\section{Epidemiology}

Estimating the prevalence of NTM-PD poses several challenges; unlike tuberculosis (TB), in most regions it is not a notifiable disease, and as the diagnosis is criteria-based, reports of isolation do not equate with clinical disease. Even allowing for these factors, however, the prevalence appears to vary widely across the globe, with particularly high annual prevalence reported in the USA and Japan of 23-37 and 33-65 cases per 100000 persons, respectively [9-11]. The prevalence of NTM-PD may also vary markedly within the same country; in a nationwide study of the USA between 1997 and 2007 the estimated period prevalence ranged from 78 cases per 100000 persons in the Midwest to 396 in Hawaii [9].

The most common species isolated globally are those in the MAC, comprising between $34 \%$ and $61 \%$ of isolates depending on continent in one systematic review, with the highest proportions found in North America and Oceania (table 1) [12]. A study of 30 predominantly European countries [13] found that M. kansasii was most common in Slovakia and Poland, M. xenopi was most common in Hungary and $M$. abscessus complex was more common in Taiwan and South Korea. While uncommon worldwide, M. malmoense was seen more frequently in Scandinavia with a prevalence of up to $5 \%$ in Norway. The proportions of different species may vary even within the same country: one study reported that the proportion of MAC varied between $61 \%$ and $91 \%$ and $M$. abscessus/chelonae between $2 \%$ and $18 \%$ across different regions of the USA [14], and in Japan a nationwide survey found marked regional differences in the ratio of M. avium to M. intracellulare and the prevalence of M. abscessus and M. kansasii [15].

Multiple studies in diverse countries have found an increase in NTM-PD prevalence over time [9-11, 1624]. Exceptions have been reported: a study in Scotland found no increase in reports of NTM isolation between 2000 and 2010 but suggested that an increase in NTM isolation may have occurred prior to the study period [25], and while a study in Canada found a marked increase in NTM isolation between 1990 and 2006, there was no increase in subjects treated for NTM and a change in laboratory techniques was felt to be responsible [26]. However, while increased case ascertainment through greater disease awareness (and hence greater sampling), improved imaging and culture techniques may play a role, the consistency of this finding across different healthcare systems and time periods suggests a genuine increase. This is supported by reports of an increase in mortality related to NTM-PD over time [11, 27]. The reason for this increase is unclear. The ageing population does not account for the increase, as it remains even when

TABLE 1 Prevalence of different nontuberculous mycobacteria species by continent

\begin{tabular}{|c|c|c|c|c|c|c|}
\hline Species & Europe & Asia & Africa & North America & Oceania & South America \\
\hline MAC & $34 \%$ & $34 \%$ & $49 \%$ & $51 \%$ & $61 \%$ & $34 \%$ \\
\hline M. abscessus & & $16 \%$ & & & $12 \%$ & \\
\hline M. fortuitum & $7 \%$ & $14 \%$ & & $7 \%$ & $12 \%$ & $9 \%$ \\
\hline M. gordonae & $18 \%$ & $9 \%$ & $6 \%$ & $13 \%$ & & $15 \%$ \\
\hline M. scrofulaceum & & & $6 \%$ & & & \\
\hline M. kansasii & & & $3 \%$ & & $3 \%$ & $17 \%$ \\
\hline M. xenopi & $15 \%$ & & & $11 \%$ & & \\
\hline Others & $26 \%$ & $27 \%$ & $36 \%$ & $18 \%$ & $12 \%$ & $25 \%$ \\
\hline
\end{tabular}

Data from ZwEIJPFENNING et al. [12]. MAC: Mycobacterium avium complex. 
adjusted for age $[10,18,22]$. One possible factor is increasing environmental exposure, which was suggested by data from the USA demonstrating an increase in sensitisation against $M$. intracellulare (assessed via skin testing) between 1971-72 and 1999-2000 [28], although the reason for an increase in exposure is not known. Interestingly the increase has not been associated with an increase in TB isolation, which in several centres was reported to have fallen over the same period [16, 18, 22, 24]. One suggested explanation for this is that TB exposure might confer cross-protection against NTM [9, 18], although changing demographic patterns may also contribute to this observation.

\section{Person-to-person transmission}

Until recently, it was thought that in contrast to TB, person-to-person spread of NTM did not occur. This was first challenged by a report of $M$. abscessus subsp. massiliense developing in four subjects at a cystic fibrosis (CF) centre in the USA following the arrival of a new patient with smear-positive disease. Pulsed-field gel electrophoresis analyses were indistinguishable between isolates, which also displayed amikacin and macrolide resistance [29]. A large retrospective study employing whole genome sequencing of 168 isolates of $M$. abscessus complex in 31 subjects with CF at a UK centre identified two clusters of subsp. massiliense showing near-identical sequences, suggesting direct spread between patients on multiple occasions. Isolates from both clusters showed resistance to clarithromycin (and amikacin in one cluster), even in subjects never exposed to these agents. Multiple opportunities for in-hospital transmission were identified although the specific mechanism could not be identified [30]. Subsequent comparison with isolates from the US outbreak revealed high-level relatedness between strains [31]. In a further multicentre global study of whole genome sequencing of 1080 isolates from 517 subjects, dominant circulating clones of subsp. massiliense and abscessus were identified that exhibited greater virulence than unclustered isolates [32]. Multiple instances of between-person transmission were again identified and opportunities were also identified for potential transmission via fomites or aerosols. A separate study has demonstrated that $M$. abscessus displays characteristics favourable to fomite spread [33]. These findings have led to the recommendation for enhanced infection control measures in CF [34]. Outside of CF, however, person-to-person transmission has not been reported.

\section{Aetiology \\ Environmental factors}

NTM are widely distributed throughout the environment, which is thought to represent the reservoir for human infection [2]. Thus, environmental factors may also mediate disease susceptibility. Measures of atmospheric moisture have been linked to increased NTM-PD prevalence $[35,36]$, presumably through increasing NTM exposure. Further evidence implicating water as a potential route of infection comes from two reports, which found isolates in the domestic water supply of subjects with NTM-PD closely resembling their respiratory isolates $[37,38]$, and an epidemiological study which found an increased risk of NTM-PD associated with specific sources supplying domestic water [39]. Soil may be another source of infection; there have been reports of the isolation of NTM from soil samples resembling those found in respiratory isolates from NTM-PD cases $[40,41]$ and exposure to soil has been identified as a risk factor for NTM-PD $[42,43]$. Beyond soil and water, NTM have also been recovered from a wide range of other environmental and domestic sources but their role in human disease is uncertain [44].

\section{Host risk factors}

A number of risk factors for NTM-PD have been identified, predominantly structural lung disease, such as bronchiectasis, chronic obstructive lung disease (COPD) and interstitial lung disease [45-49]. CF appears to be a particularly strong risk factor for NTM-PD, with a reported prevalence of between $6 \%$ and $13 \%$, and a particularly high proportion of $M$. abscessus (ranging from 16\% to 68\%) [50], which appears particularly well adapted to the CF lung [51, 52]. A high prevalence has also been reported in primary ciliary dyskinesia [53,54] and a recent novel study found reduced nasal nitric oxide and ciliary beat frequency in subjects with NTM-PD [55].

It has long been recognised that NTM-PD, usually of the nodular bronchiectatic pattern, may also develop in subjects with no previously diagnosed underlying risk factors [56-59]. This was termed the "Lady Windermere" syndrome, after the fastidious character in the eponymous play by Oscar Wilde, as the authors of the original report hypothesised that voluntary cough suppression may be the cause [56]. The majority of subjects are female, postmenopausal, taller and thinner than average, with a higher than average prevalence of thoracic skeletal abnormalities. This phenotype has led to more plausible speculation that hormonal factors, connective tissue abnormalities or low adiposity may play a role in disease susceptibility [60-62].

Increasing age has also been shown to be a strong risk factor for NTM-PD with a dramatic increase in prevalence seen in older age groups $[9-11,17,18,20-22,25]$. Many studies have also reported a higher 
prevalence observed in females [9-11, 22], although this finding is not reported in studies outside Japan and North America [17, 20, 21, 23-25].

An increased risk of NTM disease has also been demonstrated with the use of immunosuppressant medications, including biological therapy against tumour necrosis factor (TNF)- $\alpha$ and oral corticosteroids $[63,64]$. Of potentially greater importance, given the number of affected individuals, are reports suggesting a link between inhaled corticosteroids (ICS) and NTM-PD [49, 65]. Two recent, large case-control studies addressed this question. Both matched controls on key demographics and controlled comparisons for a large number of potential confounders. The first found that ICS use within the past year was associated with an increased risk of NTM-PD (adjusted odds ratio 2.8) in a cohort of subjects with asthma, COPD and bronchiectasis [66]. The second larger study found that current (but not past) ICS use was significantly associated with NTM-PD (adjusted odds ratio of 1.86), but not TB, in a cohort with obstructive lung disease. A significantly higher risk was seen with fluticasone, even when adjusted to beclomethasone dose equivalents [67]. Both studies showed a significant relationship between increasing doses of ICS and the risk of NTM-PD. While there may still be unmeasured differences between groups confounding these analyses, such as the severity of airflow obstruction, together they represent the strongest evidence to date that ICS use may contribute towards the risk of NTM-PD.

\section{Immunological factors}

The role of immunodeficiency in predisposing towards NTM disease was first brought to light by the AIDS pandemic, where reduced CD4+ counts were associated with disseminated MAC infection [68]. Disseminated mycobacterial infection is also seen in individuals harbouring mutations affecting the interferon (IFN)- $\gamma$-interleukin (IL)-12 pathway, collectively referred to as Mendelian susceptibility to mycobacterial disease. To date, mutations have been identified affecting 11 genes [69]. Outside of this pathway, mutations in GATA2 have been described, leading to defective haematopoesis and susceptibility to multiple infections, including NTM [70]. More recently, reports emerged of disseminated NTM disease affecting previous healthy, apparently immunocompetent individuals in Thailand and Taiwan traced to an inhibitory anti-IFN- $\gamma$ autoantibody [71]. These systemic immune defects generally present with disseminated rather than pulmonary disease (although elevated levels of autoantibodies against IFN- $\gamma$ and granulocyte-macrophage colony-stimulating factor (GM-CSF) have been reported in one series of subjects with NTM-PD [72]). Several studies of individuals with pulmonary disease have examined their immune responses, although the methodologies employed have varied widely and the findings have been inconsistent (table 2).

No evidence of deficiency in CD4+ T-cells has been demonstrated in subjects with NTM-PD [58, 73, 74]. However, several studies have found diminished Th1 responses, showing reduced IL-12 [74, 76, 77, 82] and IFN- $\gamma[58,62,73-75,77,79,81]$ release, although intact or increased responses have also been reported [58, 78, 80, 83]. One study found increased antibodies against IFN- $\gamma$ in subjects with NTM-PD [72]. TNF- $\alpha$ also plays an essential role in the defence against TB by activating macrophages and maintaining granuloma integrity [84]; several studies have also reported impaired TNF- $\alpha$ release in subjects with NTM-PD [58, 73, 74, 76, 77, 81-83], although intact or elevated responses have also been found $[62,83]$.

IL-10 is an anti-inflammatory cytokine which plays an important role in regulating the immune responses to prevent immunopathology, although this may be detrimental to the defence against some pathogens, including $M$. tuberculosis [85]. Studies of IL-10 responses in patients with NTM-PD have been inconsistent, with reports of increased [74, 78], unchanged [77] or decreased [62] activity. The release of another anti-inflammatory cytokine, transforming growth factor- $\beta$ [86], and the expression of the immunoregulatory protein PD-1 [81-83] have also been shown to be increased in subjects with NTM-PD compared with controls.

The role of the pro-inflammatory cytokine IL-17 in the host response to TB is complex; deficiency impairs control of $M$. tuberculosis infection in murine models; however, it has also been implicated in neutrophil-mediated immunopathology [87]. Two studies in subjects with MAC have found impaired IL-17 responses [78, 82] and in subjects with CF and $M$. abscessus, impaired IL-17 release has also been reported [80], although in contrast another report found higher circulating levels [88].

Toll-like receptors (TLRs) play an important early role in the innate host response to mycobacteria [89]. One study demonstrated a reduced TLR2 transcriptional response in patients with NTM-PD [76], and abnormalities in the ciliary beat frequency response to TLR stimulation in epithelial cells from subjects with NTM-PD have also been reported [55].

One study examined the global transcriptional response in NTM-PD through analysis of whole blood gene expression [90]. Genes involved in T-cell signalling were underexpressed in NTM-PD, including IFNG, 
TABLE 2 Summary of functional immunological studies in subjects with nontuberculous mycobacterial pulmonary disease (NTM-PD)

Study Population

Methodology

Principal findings in NTM-PD

Cell type Mitogen(s) Readout

(s)

$\begin{array}{ccccc}\text { GREINERT et al. } & 32 \text { subjects with NTM-PD\#, } 30 \text { subjects with MTB, } & \text { PBMC, } & \text { PHA, anti-CD3 Ab, PPD, } & \text { IFN- } \gamma \text { and TNF- } \alpha \text { (ELISA); CD3, CD2, CD4, } \\ \text { [73] (2000) } & 20 \text { healthy controls } & \text { whole } & \text { NDV, live M. avium, } & \text { CD8, CD38, CD20, CD16, CD57, CD45RA, } \\ & & \text { blood } & \text { M. kansasii, and M. } & \text { CD45R0, HLA-DR, CD14 (FC) }\end{array}$ szulgai

Compared to MTB controls: Lower anti-CD3 induced TNF- $\alpha$ and IFN- $\gamma$ production in PBMC; lower PPD induced IFN- $\gamma$ and TNF- $\alpha$ release in PBMC and whole blood; lower PHA induced TNF- $\alpha$ response in whole blood Compared to healthy controls: Lower anti-CD3 induced IFN- $\gamma$ production in PBMC

VANKAYALAPATI 26 subjects with NTM-PD" (all MAC),

et al. [74] 19 M. avium-sensitised healthy controls

(2001)

PBMC

Heat-killed MAC or MTB

SaFDar et al.

[75] (2003)

2 subjects with nodular NTM-PD", 39 healthy controls

RYu et al. [76] 17 subjects with nodular NTM-PD ${ }^{\#}$ and 10 healthy PBM (2007) controls

Kwon et al. [77] 29 subjects with nodular NTM-PD\#, 15 healthy (2007) controls

KIM et al. [58] 55 subjects with NTM-PD, healthy blood bank (2008) controls ${ }^{+}$

PBMC

PBMC$$
\begin{aligned}
& \text { PHA, PHA+IL-12 } \\
& \text { LPS+IFN- } \gamma
\end{aligned}
$$

PHA, PHA+IL-12 heterodimer, LPS, LPS+IFN- $\gamma$

Lim et al. [78] 17 subjects with NTM-PD, 15 healthy offspring, 13 PBMC (2010) healthy controls

\footnotetext{
KARTALIJA et al. 47 subjects with NTM-PD, 53 healthy controls Whole [62] (2013) blood

RAE et al. [79] 2 subjects with NTM-PD?", controls not stated (2016)

Whole blood

LPS, heat-killed $S$. epidermis, live $M$ intracellulare

IL-1B, IL-6, IL-8, IL-10, IL-12, IFN- $\gamma$, TNF- $\alpha$ RANTES (ELISA)

IL-12+BCG, IL-12+LPS, IFN- $\gamma^{\S}$

IL-12+PHA, IL-12

$+\mathrm{IL}-18$

PBMC

BeCKer et al. 3 patients with CF and NTM-PD" lall M.

[80] (2016) abscessus), 7 non-CF subjects with NTM-PD"

11 healthy controls

Heat-killed M. abscessus, TNF- $\alpha$, IL-1B, IFN- $\gamma$, IL-17, IL-22 (ELISA) heat-killed C. albicans,

LPS, A. fumigatus

conidia
}

SEB, tuberculin PPD, individualised NTM sensitin $\mathrm{PPD}$, anti-CD28 Ab, anti-CD49d Ab
IFN- $\gamma, I L-4, I L-18$ and IL- 10 and IFN- $\gamma$ (FC)

IFN- $\gamma$ (ELISA, FC)

TLR2, IL-12p40, TNF- $\alpha$ (RT-PCR)

Reduced IFN- $\gamma$, TNF- $\alpha$, IL-12 and IL-18, and increased $I L-10$ response to MAC

Reduced IFN- $\gamma$ response to PMA and anti-CD3 Ab

Reduced TLR2 expression in response to $M A C$; reduced resting expression of $\mathrm{IL}-12 \mathrm{p} 40$ and $\mathrm{TNF}-\alpha$ and in response to MAC and LTA

Reduced IFN- $\gamma$ response to PHA+IL-12, reduced TNF- $\alpha$ and IL-12p40 response to LPS+IFN- $\gamma$

FN- $\gamma$, TNF- $\alpha$, IL-6, IL-10, IL-1b and IL-12 Decreased IFN- $\gamma$ response to PHA+IL-12 and (bioluminescent bead assay); CD2, CD3, CD4, CD8, CD28, CD57, HLA-DR, CD25, CD20, CD16, CD56 (FC); PCR of immunoglobulin heavy chain and T-cell receptor $\gamma$-chain

CD3, CD4, IFN- $\gamma$, IL-10, IL-17A (FC); IFN- $\gamma$, Compared to healthy controls: Increased IL-5, IL-17A, IL-10 (ELISA)

$L-1 B$ response to LPS; abnormat $T-c e l l$ receptor $\gamma$-chain rearrangement patterns seen in $36 \%$ $\mathrm{CD} 4+$ IFN- $\gamma$ T-cells in response to sensitin; preserved or increased IFN- $\gamma$ secretion in response to SEB and sensitin; increased IL-10 response to tuberculin and sensitin

Decreased IFN- $\gamma$ response to MAC and LPS; lower unstimulated IL-10 levels and decreased IL-10 response to LPS, S. epidermis and MAC

Reduced IFN- $\gamma$ response to IL-12+BCG and IL-12+LPS in both subjects; IFN- $\gamma$ response to IL-12+PHA and IL-12+IL-18 reduced in one subject but preserved in the other

Increased IL-1B and TNF- $\alpha$ response to $A$ fumigatus in CF NTM-PD group; reduced IL-17 response to M. abscessus in both NTM-PD groups; preserved or elevated IFN- $\gamma$ and IL-22 response to $M$. abscessus in CF NTM-PD group 


\begin{tabular}{|c|c|c|c|c|c|}
\hline \multirow[t]{2}{*}{ Study } & \multirow[t]{2}{*}{ Population } & \multicolumn{3}{|c|}{ Methodology } & \multirow[t]{2}{*}{ Principal findings in NTM-PD } \\
\hline & & $\begin{array}{l}\text { Cell type } \\
\text { (s) }\end{array}$ & Mitogen(s) & Readout & \\
\hline $\begin{array}{l}\text { SHu et al. [81] } \\
\text { (2017) }\end{array}$ & $\begin{array}{l}50 \text { subjects with NTM-PD (all MAC) and } 30 \text { healthy } \\
\text { controls }\end{array}$ & PBMC & $\begin{array}{l}\text { Heat-killed MAC, MAC } \\
\text { sensitin, PHA }\end{array}$ & $\begin{array}{l}\text { CD3, CD4, CD25, CD14, CD19, CD56, PD-1, } \\
\text { PD-L1, PD-L2, IFN- } \gamma \text { (FC); IFN- } \gamma \text {, TNF- } \alpha \\
\text { and IL-1 } \beta \text { (ELISA), apoptosis measured by } \\
\text { Annexin V and SYTOX staining }\end{array}$ & $\begin{array}{l}\text { Impaired TNF- } \alpha \text { response to all stimuli; } \\
\text { impaired IFN- } \gamma \text { response to MAC and MAC } \\
\text { sensitin; increased PD-1 and PD-L1 } \\
\text { expression in unstimulated CD3, CD4, } \\
\text { CD8, CD19, CD56 and CD4+CD25+ T-cells; } \\
\text { higher apoptosis status in unstimulated } \\
\text { CD4 lymphocytes; higher PD-1 expression } \\
\text { and apoptosis in response to MAC } \\
\text { stimulation }\end{array}$ \\
\hline $\begin{array}{l}\text { SHu et al. [82] } \\
\text { (2018) }\end{array}$ & $\begin{array}{l}50 \text { subjects with NTM-PD (all MAC), } 25 \text { MTB } \\
\text { controls and } 25 \text { healthy controls }\end{array}$ & $\begin{array}{l}\text { Plasma, } \\
\text { MDM }\end{array}$ & Heat-killed MAC, LPS & $\begin{array}{l}\text { CD4, IL17, PD-1 (FC); IL-12p40, IL-12p70, } \\
\text { IL-23, IFN- } \gamma \text {, IL-17A (ELISA); TNF- } \alpha \\
\text { IL-12p40, IL-12p35, IL-13p19 (RT-PCR) }\end{array}$ & $\begin{array}{l}\text { Compared to MTB controls: Higher resting } \\
\text { plasma levels of IL-17 and IL-12p70; } \\
\text { lower resting levels of TNF- } \alpha \text { and IFN- } \gamma \text {; } \\
\text { reduced TNF- } \alpha \text { and IL12p40 response to } \\
\text { MAC } \\
\text { Compared to healthy controls: Higher } \\
\text { resting plasma levels of TNF- } \alpha \text {, IFN- } \gamma \text {, } \\
\text { IL-23 and IL-17; lower resting levels of } \\
\text { IL-12p70; reduced TNF- } \alpha \text { and IL12p40 } \\
\text { response to MAC; reduced IL-17 secretion } \\
\text { and increased PD-1 expression on CD4+ } \\
\text { IL- } 17+\text { T-cells in co-culture assay }\end{array}$ \\
\hline $\begin{array}{l}\text { Lutzky et al. } \\
\text { [83] (2018) }\end{array}$ & $\begin{array}{l}6 \text { subjects with CF and active NTM-PD", } 8 \\
\text { subjects with CF and successfully treated } \\
\text { NTM-PD", } 9 \text { CF controls, } 10 \text { non-CF subjects } \\
\text { with NTM-PD" and } 10 \text { healthy controls; all NTM } \\
\text { was M. abscessus }\end{array}$ & PBMC & PMA & $\begin{array}{l}\text { CD4, CD8, CD16, CD19, CD14, Tim-3, CD25, } \\
\text { PD-1, CTLA-4, FOXP3, CD107, CD3, IFN- } \gamma \text {, } \\
\text { TNF- } \alpha, \text { IL-2 (FC) }\end{array}$ & $\begin{array}{l}\text { CF group: Increased number of resting } T_{\text {reg }} \\
\text { cells in active NTM-PD compared with } \\
\text { both control groups; higher numbers of } \\
\text { resting IFN- } \gamma+\text { CD4 cells and increased } \\
\text { CD25 and CTLA- } 4 \text { expression in resting } \\
\text { CD4 cells in active NTM-PD compared to } \\
\text { uninfected controls; higher number of } \\
\text { CTLA- } 4+C D 4 \text { cells, fewer TNF- } \alpha+\text { CD } 4 \\
\text { T-cells and more IFN- } \gamma+\text { CD } 8 \text {-cells } \\
\text { following stimulation in active or previous } \\
\text { NTM-PD compared with uninfected } \\
\text { controls } \\
\text { Non-CF NTM-PD: Increased number of } \\
\text { resting Treg and CD25+PD-1+ cells; } \\
\text { increased resting CD25, CTLA- } 4 \text { and PD-1 } \\
\text { expression; increased TNF- } \alpha+C D 8+ \\
\text { T-cells in response to PMA }\end{array}$ \\
\hline
\end{tabular}

Selected methodological details and findings are given; for full methods and findings please refer to the original papers. Subjects with NTM-PD were diagnosed by the American Thoracic Society (ATS) 2007 criteria unless otherwise stated. MTB: M. tuberculosis; PBMC: peripheral blood mononuclear cells; PBM: peripheral blood monocytes; PHA: phytohemagglutinin; Ab: antibody; PPD: purified protein derivative; NDV: Newcastle disease virus; IFN: interferon; TNF: tumour necrosis factor; HLA-DR: human leukocyte antigen DR isotype; MAC: M. avium complex; IL: interleukin; LPS: lipopolysaccharide; FC: flow cytometry; RANTES: regulated on activation, normal T-cell expressed and secreted; LTA: lipoteichoic acid; MDM: monocyte-derived macrophages; PMA: phorbal 12-myristate 13-acetate; BCG: bacillus Calmette-Guérin; PD-L1: programmed death ligand 1; SEB: staphylococcal enterotoxin B; CF: cystic fibrosis; CTLA-4: cytotoxic T-lymphocyte antigen 4; $T_{\text {reg }}$ : regulatory T-cells. ${ }^{\#}$ : ATS 1997 criteria; ${ }^{\text {П }}$ : other diagnostic criteria, or not stated; ${ }^{+}$: number of subjects not stated; : method not stated. 
which encodes IFN- $\gamma$. In subjects with NTM-PD, increased expression of genes involved in innate immunity and inflammation was associated with increased mortality, whereas expression of genes relating to $\mathrm{T}$ - and B-cell function were associated with survival.

The interpretation of these data is clouded by the potential immunomodulatory effect of mycobacterial infection on the immune response [91], as well as differences in study populations and the methodologies used. The weight of the evidence thus far suggests downregulation of the immune response in NTM-PD, although whether this is truly a predisposing factor or a result of disease remains unresolved. Furthermore, it is likely that immune responses vary according to the pattern or severity of disease and the NTM species.

\section{Genetics}

As with M. tuberculosis [92], it has been suggested that there may be a genetic contribution to disease susceptibility, supported by reports of familial clustering of NTM-PD [93]. Several studies have examined candidate genes related to the host response, with mixed results (table 3). Studies of human leukocyte antigens have variously associated the DR6 and A26 alleles and the A2-B21 haplotype with NTM disease [106, 114-116]. Mutations in the murine Nramp1 gene confer susceptibility to mycobacterial disease; heterozygosity for three polymorphisms in the human homologue NRAMP1 were associated with NTM-PD in one cohort [97], but conflicting findings were seen in a second study which reported a higher prevalence of homozygotes for two of these polymorphism in NTM-PD [102]. Two earlier studies found no relationship [94, 96]. While an earlier small study found no link between two polymorphisms in IFNGR1 and NTM-PD [94], a recent study found a higher prevalence of the T-56C polymorphism [109]. Mutations linked with NTM-PD have also been reported in IL10, IL28, TNFA and an intron II of TLR2 $[105,107,111]$, but studies of IL12RB1, MBL and two polymorphisms in TLR2 previously linked to mycobacterial disease found no association [99, 102, 103].

The high incidence of NTM-PD seen in CF has led to CFTR being proposed as a candidate gene for disease susceptibility, and the incidence of CFTR mutations in patients with NTM-PD disease is significantly higher than the general population. The reported proportion of NTM-PD patients with CFTR mutations ranges from $21 \%$ to $44 \%$ and the proportion with a sweat chloride $>60 \mathrm{mmol} \cdot \mathrm{L}^{-1}$ ranges from $3 \%$ to $22 \%[46,58,98,100]$. Studies in Asian populations with a low prevalence of CF have also demonstrated an association between CFTR polymorphisms and NTM-PD [101, 108]. One retrospective study addressed the issue of whether CFTR mutation merely predisposes towards bronchiectasis, which is in itself a risk factor for NTM-PD, or is independently associated [46]. The authors found a significantly higher incidence of CFTR mutation in patients with NTM-PD and bronchiectasis versus bronchiectasis alone (22\% versus $5 \%)$, despite a similar proportion of each group receiving screening.

Other genes which have been linked to NTM-PD include alpha-1 antitrypsin (AAT) in two studies [98, 117], the vitamin D receptor $(V D R)$ in one study [95], although this has not been replicated in Korean and Japanese populations [102, 104], and the macrophage stimulating 1 receptor (MSTR1) in a cohort of subjects with NTM-PD and thoracic skeletal abnormalities, where it was associated with reduced IFN- $\gamma$ responses [112].

Two recent studies have utilised whole exome sequencing to search for genetic factors conferring susceptibility to NTM-PD. The first study performed whole exome sequencing on 69 subjects with NTM-PD and 18 unaffected relatives [110], focusing on genes in four candidate categories: immune, cilia, connective tissue and CFTR. NTM-PD cases were more likely to have variants in all categories compared with population controls. Interestingly, a higher number of variants were also seen in unaffected family members of NTM-PD cases compared with controls, except for immune-related genes where variants were observed almost exclusively in NTM-PD cases, perhaps indicating a particularly important role in mediating susceptibility to disease. CFTR variants were seen in $26 \%$ of subjects with NTM-PD (and $44 \%$ of unaffected relatives) compared with a population prevalence of $6 \%$. An unbiased exome-wide search was also conducted to find any novel genes associated with NTM-PD which identified 89 genes, 53\% of which belonged to one of the candidate categories.

The second study was conducted on the same cohort and used a genome-wide linkage analysis of nine families with NTM-PD, identifying a 20cM region of chromosome 6 with evidence of linkage [113]. At the gene level this was most significant for TTK which encodes a protein involved in cell division and replication, but linkage was also seen with TPBG, ORC3 and ANKRD6. In a further genome-based association analysis, five genes reached genome-wide significance, including $M A P 2 K 4$, which plays a role in TLR signalling, and IFNLR1, which encodes part of the receptor for IFN- $\lambda$.

As with the literature on immune defects in NTM-PD, interpretation of the result of these studies is complicated by the differing methodology used between studies performed in different populations of 
TABLE 3 Summary of genetic studies in nontuberculous mycobacterial pulmonary disease (NTM-PD)

\begin{tabular}{|c|c|c|c|c|c|}
\hline Study & Gene(s) examined & Population & Country & Methodology & Principal findings in NTM-PD \\
\hline $\begin{array}{l}\text { HuANG et al. } \\
\text { [94] (1998) }\end{array}$ & NRAMP1, IFNGR1 & $\begin{array}{l}8 \text { subjects with NTM-PD\# }, 22 \\
\text { healthy controls }\end{array}$ & USA & $\begin{array}{l}\text { NRAMP1: PCR, HPLC and partial sequencing to } \\
\text { detect G105D polymorphism; PCR and RFLP of } \\
\text { D543N and 3'UTR polymorphisms; PCR and } \\
\text { microsatellite sizing of promoter region } \\
\text { polymorphism. } \\
\text { IFNGR1: PCR and RFLP for nucleotide } 395 \\
\text { polymorphism; PCR and HPLC for nucleotide } 131 \\
\text { polymorphism }\end{array}$ & No polymorphisms were associated with NTM-PD \\
\hline $\begin{array}{l}\text { GELDER et al. } \\
\text { [95] (2000) }\end{array}$ & $V D R$ & $\begin{array}{l}56 \text { subjects with NTM-PD lall } \\
\text { M. malmoense), } 101 \text { healthy } \\
\text { controls }\end{array}$ & UK & $\begin{array}{l}\text { PCR and RFLP for Fokl, Apal and Taql } \\
\text { polymorphisms }\end{array}$ & $\begin{array}{l}\text { Higher prevalence of Taql } \mathrm{t} \text { and Apal A alleles and } \\
\text { lower prevalence of Fokl } \mathrm{f} \text { alleles in NTM-PD }\end{array}$ \\
\hline $\begin{array}{l}\text { TANAKA et al. } \\
\text { [96] (2000) }\end{array}$ & NRAMP1 & $\begin{array}{l}4 \text { pairs of related subjects } \\
\text { with NTM-PD" }\end{array}$ & Japan & Sequencing of NRAMP1 & $\begin{array}{l}\text { Heterozygous missense mutation at codon } 419 \text { in } \\
\text { one subject; no other relevant polymorphisms } \\
\text { identified }\end{array}$ \\
\hline $\begin{array}{l}\text { KoH et al. [97] } \\
\text { (2005) }\end{array}$ & NRAMP1 & $\begin{array}{l}41 \text { subjects with NTM-PD }, 50 \\
\text { healthy controls }\end{array}$ & $\begin{array}{l}\text { South } \\
\quad \text { Korea }\end{array}$ & $\begin{array}{l}\text { PCR and RFLP of INT4, D543N and 3'UTR } \\
\text { polymorphisms }\end{array}$ & $\begin{array}{l}\text { Higher rate of heterozygotes at INT4 (G/C), D543N } \\
\text { (G/A) and 3'UTR (TGTG ins/del) in NTM-PD }\end{array}$ \\
\hline $\begin{array}{l}\text { Kıм et al. [98] } \\
\text { (2005) }\end{array}$ & CFTR & 85 subjects with NTM-PD & USA & Oligonucleotide probe panel (86 mutations) & $\begin{array}{l}\text { Variants seen in } 15 \text { subjects ( } \Delta \mathrm{F} 508, w 1282 \mathrm{x}, \mathrm{R} 117 \mathrm{H} \\
\text { and } \mathrm{D} 11152 \mathrm{H} \text { ) }\end{array}$ \\
\hline $\begin{array}{l}\text { FowLer et al. } \\
\text { [46] (2006) }\end{array}$ & CFTR & $\begin{array}{l}98 \text { subjects with } \\
\text { bronchiectasis (10 with } \\
\text { positive sputum NTM } \\
\text { culture) }\end{array}$ & UK & $\begin{array}{l}\text { Screening panel for } \Delta \text { F508, G85E, R117H, } 621 \\
\quad+1 G>T, G 551 D, R 553 X, G 542 X, N 1303 X \text {, and } \Delta 1507 \\
\text { variants }\end{array}$ & $\begin{array}{l}\text { Variants found in } 2 / 9 \text { subjects with NTM isolated } \\
\text { compared with } 4 / 77 \text { of non-NTM subjects }\end{array}$ \\
\hline $\begin{array}{l}\text { Ryu et al. [99] } \\
\text { (2006) }\end{array}$ & $T L R 2$ & $\begin{array}{l}80 \text { subjects with nodular } \\
\text { NTM-PD }{ }^{\#} \text { and } 84 \text { healthy } \\
\text { volunteers }\end{array}$ & $\begin{array}{l}\text { South } \\
\text { Korea }\end{array}$ & $\begin{array}{l}\text { PCR and RFLP of Arg677Trp and Arg753Gln } \\
\text { polymorphisms }\end{array}$ & No polymorphisms were associated with NTM-PD \\
\hline $\begin{array}{l}\text { ZIEDALSKI et al. } \\
{[100]} \\
\text { (2006) }\end{array}$ & CFTR & $\begin{array}{l}50 \text { subjects with } \\
\text { bronchiectasis, of whom } 30 \\
\text { had NTM-PD\# }\end{array}$ & USA & $\begin{array}{l}\text { PCR-based commercial screening assay }(>1300 \\
\text { mutations) }\end{array}$ & $\begin{array}{l}\text { Variants seen in 14/30 NTM-PD subjects and 10/20 } \\
\text { non-NTM subjects }\end{array}$ \\
\hline $\begin{array}{l}\text { MAl et al. } \\
\text { [101] } \\
\text { (2007) }\end{array}$ & CFTR & $\begin{array}{l}300 \text { subjects with NTM-PD } \\
\text { (all MAC), } 100 \text { healthy } \\
\text { controls }\end{array}$ & Japan & $\begin{array}{l}\text { PCR and RFLP to detect M470V polymorphism in } \\
\text { exon } 10, P C R \text { and sequencing of poly-T and TG } \\
\text { repeats in intron } 8 \text { (IVS8) }\end{array}$ & Higher rate of IVS8T5 allele in NTM-PD \\
\hline $\begin{array}{l}\text { TANAKA et al. } \\
\text { [102] } \\
\text { (2007) }\end{array}$ & NRAMP1, VDR, MBL & $\begin{array}{l}111 \text { subjects with NTM-PD\# } \\
\text { (all MAC), two groups of } \\
177 \text { and } 247 \text { healthy } \\
\text { controls }\end{array}$ & Japan & $\begin{array}{l}\text { NRAMP1: PCR and sequencing of INT4, 3'UTR and } \\
\text { D543N polymorphisms } \\
\text { VDR: PCR and RFLP of Fokl and Taql } \\
\text { polymorphisms } \\
\text { MBL: PCR and RFLP of rs7096206 and rs } 1800450 \\
\text { SNPs }\end{array}$ & $\begin{array}{l}\text { Higher rates of homozygotes for major alleles of } \\
\text { D543N (G/G) and 3'UTR (TGTG ins/ins) of NRAMP1 } \\
\text { in NTM-PD; no polymorphisms in VDR or MBL } \\
\text { were associated with NTM-PD }\end{array}$ \\
\hline $\begin{array}{l}\text { Kıм et al. [58] } \\
\text { (2008) }\end{array}$ & CFTR & $\begin{array}{l}63 \text { subjects with NTM-PD, } 32 \\
\text { healthy controls }\end{array}$ & USA & $\begin{array}{l}\text { Commercial screening panel and sequencing of } \\
\text { exons } 1-27,5^{\prime} \text { and } 3^{\prime} \text { untranslated regions, } 15 \\
\text { intronic bases flanking each exon and } 1000 \text { bp } 5^{\prime} \\
\text { of exon } 1\end{array}$ & $\begin{array}{l}\text { Variants found in } 36.5 \% \text { of subjects with NTM-PD } \\
\text { compared with } 15.6 \% \text { of controls, including } \\
\text { delF508, R117H, V754M, D1152H, R75Q, S1235R, } \\
\text { G576A, R668C, R31C and R1162L }\end{array}$ \\
\hline $\begin{array}{l}\text { PARK et al. } \\
\text { [103] } \\
\text { (2008) }\end{array}$ & IL12RB1 & $\begin{array}{l}128 \text { subjects with nodular } \\
\text { NTM-PD, } 240 \text { healthy } \\
\text { controls }\end{array}$ & $\begin{array}{l}\text { South } \\
\text { Korea }\end{array}$ & $\begin{array}{l}\text { PCR and sequencing of }+705 \mathrm{~A} / \mathrm{G},+1158 \mathrm{~T} / \mathrm{C} \text {, and } \\
+1196 \mathrm{G} / \mathrm{C} \text { SNPs }\end{array}$ & No polymorphisms were associated with NTM-PD \\
\hline $\begin{array}{l}\text { PARK et al. } \\
\text { [104] } \\
\text { (2008) }\end{array}$ & $V D R$ & $\begin{array}{l}124 \text { subjects with nodule } \\
\text { NTM-PD\#, } 127 \text { healthy } \\
\text { controls }\end{array}$ & $\begin{array}{l}\text { South } \\
\quad \text { Korea }\end{array}$ & PCR and RFLP for Fokl and Taq/ polymorphisms & No difference between groups \\
\hline
\end{tabular}




\begin{tabular}{|c|c|c|c|c|c|}
\hline Study & Gene(s) examined & Population & Country & Methodology & Principal findings in NTM-PD \\
\hline $\begin{array}{l}\text { YIM et al. } \\
\text { [105] } \\
\text { (2008) }\end{array}$ & TLR2 & $\begin{array}{l}193 \text { subjects with nodular } \\
\text { NTM-PD\# } 191 \text { controls }\end{array}$ & $\begin{array}{l}\text { South } \\
\text { Korea }\end{array}$ & PCR of $150 \mathrm{bp}$ region surrounding GT repeat & $\begin{array}{l}\text { Short GT repeats more common in NTM-PD; } \\
\text { S-alleles more common in NTM-PD compared } \\
\text { with controls in MAC, but not M. abscessus }\end{array}$ \\
\hline $\begin{array}{l}\text { Matsuyama } \\
\text { et al. [106] } \\
\text { (2010) }\end{array}$ & CFTR, NRAMP1+ & $\begin{array}{l}\text { Five members ( } 3 \text { affected) of } \\
\text { family with outbreak of } \\
\text { MAC NTN-PD" }\end{array}$ & Japan & $\begin{array}{l}\text { CFTR: Commercial screening panel and PCR and } \\
\text { sequencing of poly-T and TG repeats in intron } 8 \\
\text { (IVS8) } \\
\text { NRAMP1: PCR and sequencing of INT4, 3'UTR } \\
\text { and D543N polymorphisms }\end{array}$ & No polymorphisms were associated with NTM-PD \\
\hline $\begin{array}{l}\text { AfFANDI et al. } \\
\text { [107] } \\
\text { (2013) }\end{array}$ & $\begin{array}{l}\text { TNFA, BAT1, IL1A, IL2, } \\
\text { IL4, IL18, CCL2, VDR, } \\
\text { CD14, IL10, IL12B, } \\
\text { SLC11A1, IL28B, }\end{array}$ & $\begin{array}{l}79 \text { subjects with NTM-PD lall } \\
\text { MACl, } 188 \text { healthy controls }\end{array}$ & Australia & $\begin{array}{l}\text { Taqman probes for } 16 \text { known SNPs (rs1800629, } \\
\text { rs1799964, rs9281523, rs17561, rs2069762, } \\
\text { rs2243250, rs187238, rs 1946518, rs1024611, } \\
\text { rs10735810, rs2569190, rs1800896, rs3212227, } \\
\text { rs17235409, rs8099917, rs12979860) }\end{array}$ & $\begin{array}{l}\text { SNPs in IL12B (rs8099917), TNFA (rs1799964) and } \\
\text { IL10 (rs1800896) associated with NTM-LD }\end{array}$ \\
\hline $\begin{array}{l}\text { JANG et al. } \\
\text { [108] } \\
\text { (2013) }\end{array}$ & CFTR & $\begin{array}{l}300 \text { subjects with NTM-PD, } \\
446 \text { healthy controls }\end{array}$ & $\begin{array}{l}\text { South } \\
\text { Korea }\end{array}$ & $\begin{array}{l}\text { Whole exon sequencing (60 NTM-PD subjects); } \\
\text { MALDI-TOF MS of identified variants }\end{array}$ & Higher frequency of $\mathrm{Q} 1352 \mathrm{H}$ variant in NTM-PD \\
\hline $\begin{array}{l}\text { FARNIA et al. } \\
\text { [109] } \\
\text { (2017) }\end{array}$ & IFNGR1 & $\begin{array}{l}80 \text { subjects with NTM-PD and } \\
80 \text { healthy volunteers }\end{array}$ & Iran & PCR and RFLP of T-56C SNP & $\begin{array}{l}\text { Significantly higher frequency of } \mathrm{C} \text {-allele in } \\
\text { NTM-PD }\end{array}$ \\
\hline $\begin{array}{l}\text { SZYMANSKI } \\
\text { et al. [110] } \\
\text { (2015) }\end{array}$ & Exome-wide & $\begin{array}{l}69 \text { subjects with NTM-PD, } 18 \\
\text { unaffected family members }\end{array}$ & USA & Whole exome sequencing & $\begin{array}{l}\text { Significantly higher number of variants in immune } \\
\text { (including STAT1, IRF8, MPEG1, CARD9), cilia } \\
\text { (including RSPH1 and MST1R) and connective } \\
\text { tissue (including FBN2 and COL5A1) related } \\
\text { genes; CFTR variants seen in } 23 \% \text { of NTM-PD } \\
\text { subjects and } 44 \% \text { of family controls }\end{array}$ \\
\hline $\begin{array}{l}\text { HALSTROM } \\
\text { et al. [111] } \\
\text { (2017) }\end{array}$ & IL10 & $\begin{array}{l}124 \text { subjects with NTM-PD, } \\
229 \text { healthy controls }\end{array}$ & Australia & $\begin{array}{l}\text { Custom TaqMan Genotyping plates for } 7 \text { known } \\
\text { SNPs (rs3024498, rs1518111, rs3021094, } \\
\text { rs3024491, rs1800872, rs1800871, rs3024497) }\end{array}$ & One SNP (rs1518111) associated with NTM-PD \\
\hline $\begin{array}{l}\text { BECKER et al. } \\
\text { [112] } \\
\text { (2017) }\end{array}$ & MST1R & $\begin{array}{l}11 \text { subjects ( } 2 \text { related) with } \\
\text { nodular NTM-PD and } \\
\text { pectus excavatum and } \\
\text { scoliosis }\end{array}$ & USA & Whole exome sequencing & $\begin{array}{l}\text { Rare missense variant ( } p . V 900 M \text { ) in MST1R seen in } \\
\text { both related subjects and } 2 \text { subjects with } \\
\text { sporadic disease; further analysis revealed the } \\
\text { same variant in } 6 \text { relatives of the familial cases. }\end{array}$ \\
\hline $\begin{array}{l}\text { CHEN et al. } \\
\text { [113] } \\
\text { (2017) }\end{array}$ & Exome-wide & $\begin{array}{l}9 \text { families with NTM-PD (16 } \\
\text { affected, } 20 \text { unaffected), } 57 \\
\text { subjects with sporadic } \\
\text { NTM-PD }\end{array}$ & USA & $\begin{array}{l}\text { Whole exome sequencing, variant-level and } \\
\text { gene-level linkage analysis }\end{array}$ & $\begin{array}{l}\text { Variant-level analysis identified a region of } \\
\text { chromosome } 6 \text { with evidence of linkage; } \\
\text { gene-level analysis of chromosome } 6 \text { found } \\
\text { suggestive linkage of the TTK gene as well as } \\
\text { TPBG, ORC3 and ANKRD6; further genome-wide } \\
\text { analysis identified variants in MAP2K4, RCOR3, } \\
\text { KRT83, IFNLR1 and SLC29A1 associated with } \\
\text { NTM-PD }\end{array}$ \\
\hline
\end{tabular}

Selected methodological details and findings are given; for full methods and findings please refer to the original papers. The nomenclature for genes and variants is that used in the original studies. Subjects with NTM-PD were diagnosed by the American Thoracic Society (ATS) 2007 criteria unless otherwise stated. RFLP: restriction fragment length polymorphism; SNP: single nucleotide polymorphism; HPLC: high performance liquid chromatography; bp: base pair; MAC: M. avium complex; MALDI-TOF MS: matrix-assisted laser desorption/ ionisation time-of-flight mass spectrometry. ${ }^{\#}$ : ATS 1997 criteria; ${ }^{\text {ๆ: }}$ other diagnostic criteria, or not stated; ${ }^{+}$: now termed SLC11A1. 
varying ethnicities. It may also be difficult to untangle whether such mutations merely predispose to bronchiectasis, which is in itself a risk factor for NTM-PD, or make an independent contribution to disease susceptibility. The weight of the evidence thus far implicates CFTR mutations as a risk factor, but the data for other genes is inconsistent. It seems increasingly likely that the genetic contribution to NTM-PD is complex and involves multiple variants in multiple pathways, making the identification of a target for intervention challenging.

\section{Diagnosis}

The diagnosis of NTM-PD depends upon the integration of clinical, radiological and microbiological findings, summarised in the American Thoracic Society and Infectious Diseases Society of America (ATS/ IDSA) 2007 criteria which have become the accepted disease definition [8]. The presenting symptoms of NTM-PD are nonspecific [118] but the radiological presentation is more suggestive, typically falling into two patterns: bronchiectasis, with nodules ("nodular bronchiectatic" disease) or cavitation with fibrosis ("fibrocavitary" disease) (figure 1) [119, 120].

\section{Detection of NTM}

To be able to apply current diagnostic criteria, a minimum of three respiratory samples should be obtained. Storage of sputum samples at either room temperature or in a refrigerator does not affect the yield of microscopy and culture of MAC bacteria, which enables home sampling and sample submission to centralised laboratories by mail [121]; this has not been investigated for other NTM. In nodular bronchiectatic disease, with its generally lower bacterial load, small cohort studies have suggested that the sensitivity of bronchoalveolar lavage sample cultures is higher than that of sputum culture $[122,123]$. In a small study of 26 patients with suspected MAC nodular bronchiectatic lung disease, bronchoalveolar lavage yielded positive cultures in 13, versus only six by sputum cultures [122]. Automated liquid culture systems have become the reference method for mycobacterial culture. Still, incubation of samples on both liquid and solid media at $37^{\circ} \mathrm{C}$ increases the sensitivity of culture (figure 2) [124].

\section{Identification of NTM isolates}

Molecular tests, being either line probe assays or gene sequencing-based approaches, are the favoured method for NTM identification. Several commercial tests detecting the most frequent species exist, although all detect a limited number of species or species complexes and have suboptimal specificity; for example, most tests fail to discriminate the species of MAC [124, 125]. Matrix-assisted laser desorption ionisation-time of flight (MALDI-TOF) mass spectrometry has revolutionised clinical bacteriology and is also useful for NTM identification, although it is a labour-intensive method and its sensitivity and specificity rely on the quality of protein extraction and the mass spectra databases of the system used [126]. Next generation sequencing of whole genomes is likely to supersede current molecular identification algorithms in the centres that have access to this technology.

Correct identification of NTM species is of paramount importance, as the different species differ in their ability to cause pulmonary disease. Identification of species well known to cause pulmonary disease (MAC,
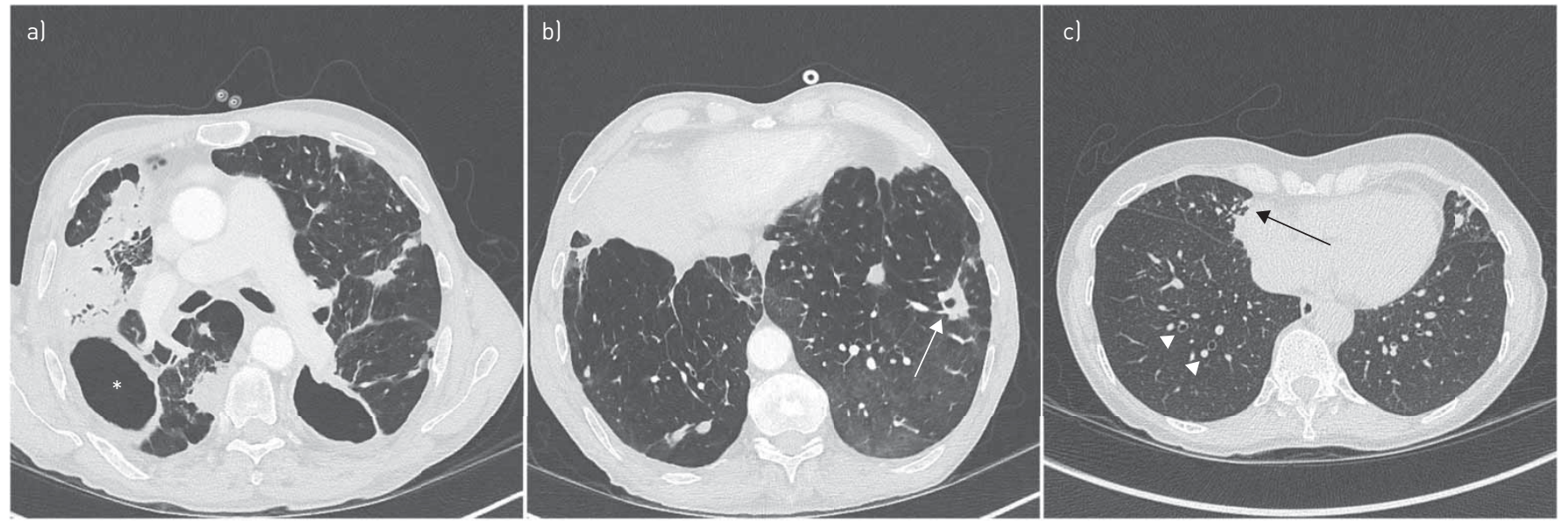

FIGURE 1 The appearance of pulmonary nontuberculous mycobacterial disease on high-resolution computed tomography: a) fibrocavitary disease, b) cavitating nodules and c) nodular bronchiectatic disease in the middle lobe and lingua in a patient with "Lady Windermere" syndrome. Asterisk: cavity; white arrow: cavitating nodule; arrowheads: bronchiectasis; black arrow: nodules. 

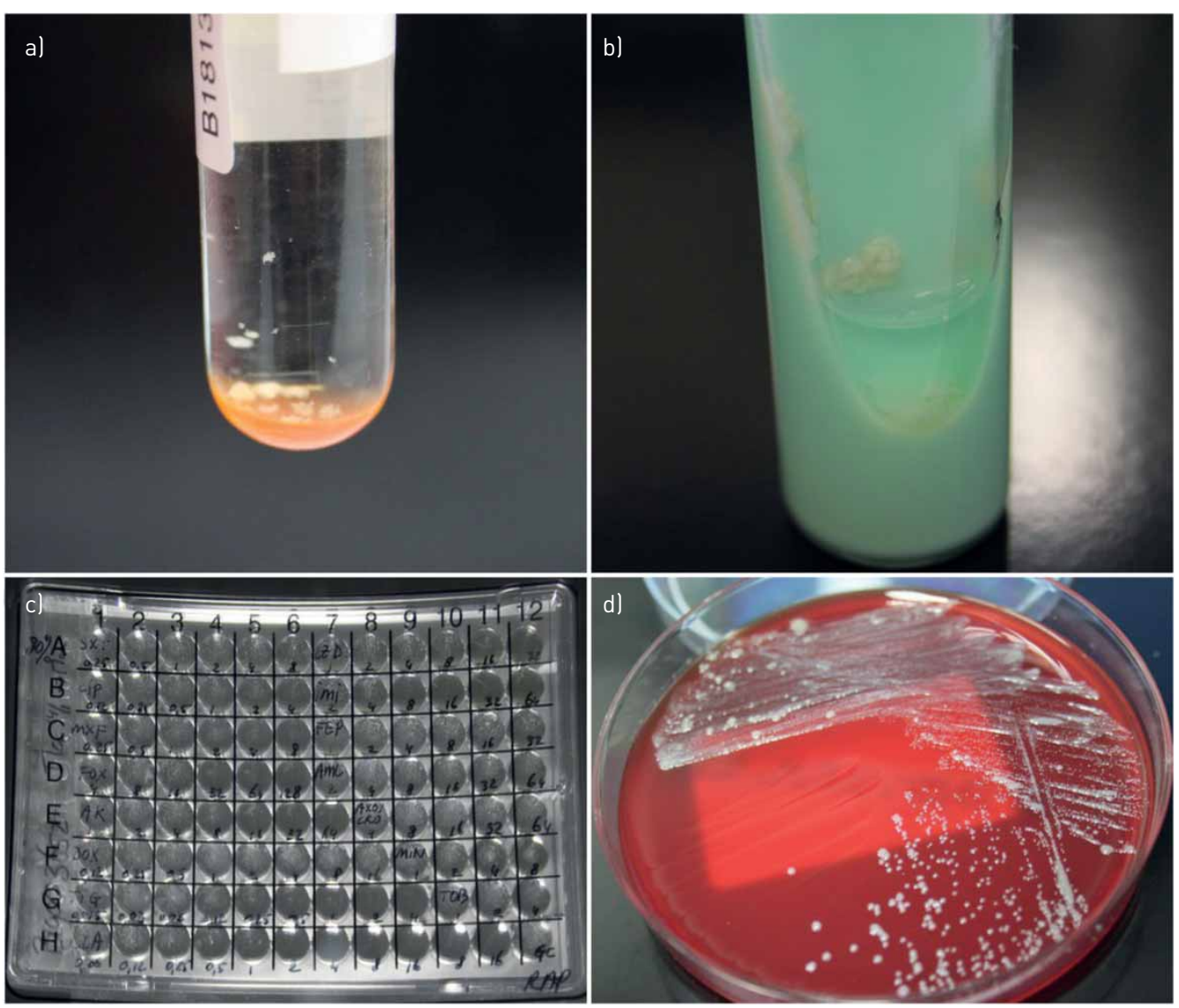

FIGURE 2 The microbiological diagnosis of pulmonary nontuberculous mycobacterial disease. a) Growth of Mycobacterium abscessus in broth medium. Mycobacteria mostly grow in clumps or flakes, at the bottom of the tube. b) Mycobacterium abscessus growing on Lowenstein-Jensen medium. The cream coloured and waxy colonies set $M$. abscessus and other nonchromogenic nontuberculous mycobacteria clearly apart from M. tuberculosis, which grows as white and drier, cauliflower-shaped colonies. c) Mycobacterium abscessus susceptibility testing by broth microdilution. d) Smooth Mycobacterium abscessus colonies on a sheep blood agar plate.

M. abscessus, M. malmoense, M. xenopi) should prompt intensive investigation, whereas samples yielding typically saprophytic species such as $M$. gordonae and $M$. chelonae might not require that, depending on the clinical background [127].

\section{Culture-free NTM detection}

While the culture of respiratory samples remains the cornerstone of diagnosis, culture-free methods offer the potential to provide a more rapid diagnosis and avoid the challenges of NTM culture.

Similar molecular methods to those used in species identification may be applied to DNA extracted from respiratory samples to directly detect and identify NTM without the need for culture [128-133]. However, the reported sensitivity is low, detecting NTM in only $29-76 \%$ of culture positive samples $[128-130,132]$, although better detection rates are reported in more heavily smear-positive samples. Most reported methods also target a limited range of species [128, 129, 132] and so will also miss rare or novel species. Nevertheless, as sequencing technology steadily advances, optimisation of these techniques may overcome these challenges and they could potentially form a part of future clinical practice.

Several studies have looked at the use of serological testing to detect NTM-PD. In a large meta-analysis of a predominantly Japanese cohort, an assay measuring IgA against glycopeptidolipid (GPL) antigens present in the cell wall of MAC reported an overall sensitivity of $69.6 \%$ and specificity of $90.6 \%$ [134]. However, significant cross-reactivity was seen with rapidly growing mycobacteria and up to $7 \%$ of healthy controls also reported a positive result. Within the CF population, measurement of IgG against the mycobacterial A60 antigen was reported to show a sensitivity of $86.7 \%$ and specificity of $95.1 \%$ for the diagnosis of $M$. abscessus disease [135], and a multi-antigen IgG assay against M. abscessus reported a 
sensitivity of $95 \%$ and specificity of $73 \%$ [136]. Both studies suggested a correlation with disease activity although the numbers were small.

While serology will not replace microbiological methods, it may have a useful role in certain circumstances, for example when obtaining repeated respiratory samples is not possible. It may be useful in disease surveillance as a means of identifying those at high risk of disease development [136], or even potentially in the monitoring of disease activity and response to treatment, although further work needs to be done in this area.

\section{Drug susceptibility testing}

Broth microdilution (figure 2c) is the recommended platform for drug susceptibility testing of NTM; technical guidance documents have been published by the Clinical Laboratory Standards Institute [137] and endorsed by the ATS/IDSA guideline on diagnosis and treatment of NTM-PD [8]. Testing susceptibility of NTM to macrolides and amikacin (and rifampicin for M. kansasii) is of clear clinical importance, as resistance to these drugs is associated with poor outcomes of treatment with these agents. For MAC, there is a clear correlation between baseline macrolide susceptibility of the causative strain and the outcome of treatment with rifampicin-ethambutol-macrolide regimens $[138,139]$. In a case series from Japan, culture conversion rates were $72 \%$ overall, but only $25 \%$ in patients whose primary MAC isolates were already macrolide resistant [139]. For amikacin, it was recently established that isolates with minimal inhibitory concentrations (MICs) $>64 \mathrm{mg} \cdot \mathrm{L}^{-1}$ typically show resistance-conferring mutations in the 16S rDNA (rrs) gene and are isolated from patients with extensive exposure to aminoglycosides [140]. Similarly, the recent clinical trial of amikacin liposome inhaled suspension (ALIS) (previously known as liposomal amikacin for inhalation) reported failure of treatment associated with baseline or acquired amikacin resistance, evidenced by MICs $>64 \mathrm{mg} \cdot \mathrm{L}^{-1}$ [141]. Based hereupon, the tentative breakpoint for resistance is an MIC $>64 \mathrm{mg} \cdot \mathrm{L}^{-1}$; such MICs should lead to cessation of amikacin therapy, as it is unlikely to improve outcomes [140,141]. Tentative breakpoints for linezolid and moxifloxacin are also provided by the Clinical Laboratory Standards Institute; for these, in vitro-in vivo correlations have not been established [137, 142].

For M. abscessus, too, in vitro-in vivo correlations are most evident for macrolides and amikacin. Resistance to macrolides may be evident on initial testing (constitutive resistance, mediated by mutation in the $23 \mathrm{~S}$ ribosomal RNA gene) or develop after incubation in macrolide-containing media after at least 14 days (inducible resistance, mediated by the erm(41) gene) [142]. Inducible macrolide resistance is present in most strains of $M$. abscessus subsp. abscessus and subsp. bolletii but absent in M. abscessus subsp. massiliense, owing to a large deletion in the erm(41) gene. In case series, it has become evident that the outcomes of macrolide-based treatment regimens are poorest in patients infected by $M$. abscessus strains with inducible macrolide resistance $(25 \%-30 \%$ culture conversion) and best in those with M. abscessus subsp. massiliense (70-80\% culture conversion) [143, 144]. In a trial of ALIS, outcomes in M. abscessus disease were poor and treatment failure occurred with the emergence of mutational resistance [145]. For other important drugs, including tigecycline and the $\beta$-lactams cefoxitin and imipenem, such studies are lacking, although pharmacodynamic models show that their efficacy is eventually annulled by emergence of resistance $[146,147]$.

For M. kansasii, susceptibility testing to rifampicin and macrolides is recommended, but only for rifampicin, there is evidence of treatment failure, with the emergence of rifampicin resistance [148]. For other NTM species, in vitro-in vivo correlations have not been studied, but drug susceptibility testing to macrolides, fluoroquinolones, linezolid, tetracyclines and aminoglycosides is used to guide treatment regimens.

\section{Treatment}

A challenging aspect of NTM disease is that, unlike TB, the diagnosis of disease does not necessitate treatment. A large study of patients with MAC found that nearly one quarter remained stable after 3 years without treatment [149], and in a series restricted to nodular bronchiectatic MAC half remained stable without treatment after a mean of 32 months follow-up [150]. A retrospective study of prognostic factors in MAC disease reported that $80 \%$ of subjects were initially treated with observation, of whom only $14 \%$ went on to receive any treatment [151]. The choice of initial observation was not associated with adverse outcomes. A series of subjects with $M$. abscessus also found more than half did not require treatment over a median follow-up of 1265 days [152]. In addition, treatment is associated with a high rate of adverse events with no guarantee of cure. The decision on who to treat and when to start treatment is therefore of great importance.

One important factor is the identity of the isolated species, as the clinical relevance varies between species [12]. The radiological pattern of disease is also highly important as cavitation has been repeatedly associated with disease progression in MAC [149-151]. Further reported multivariate predictors of disease 
progression requiring treatment in one study of MAC were increased age, lower body mass index (BMI), presence of systemic symptoms, positive sputum smear and the number of involved lobes [149].

Predictors of mortality may also help guide treatment decisions, although it must be borne in mind that these will not identify subjects in whom treatment is more likely to be successful, but rather those with a poor prognosis even with treatment. Such factors include: cavitary, consolidative or infiltrative radiological patterns, male sex, increasing age, low income, higher healthcare utilisation, low BMI, low forced vital capacity, haemoptysis, low albumin, lymphopaenia, raised erythrocyte sedimentation rate, anaemia, previous $\mathrm{TB}$, the presence of comorbidities, immunosuppression, chronic pulmonary aspergillosis and pulmonary hypertension [151,153-160]. A summary of the factors to be considered in the decision to treat is shown in figure 3.

Before starting treatment, the management of the underlying lung disease and associated comorbidities should be optimised, including treatment of other pathogens, such as Pseudomonas. Consideration should also be given to the ultimate goal of treatment. While in most cases treatment may be given with curative intent, in some circumstances a cure may not be achievable and treatment aimed at stabilising disease progression and controlling symptoms. In this scenario a less efficacious but better-tolerated regimen may be selected, particularly in the elderly, who are at increased risk of drug intolerance. In contrast, in the context of CF, infection with $M$. abscessus may preclude transplantation and an aggressive approach aimed at maximising the chance of cure at the expense of an increased risk of adverse events may be chosen. In each case the management plan should be formulated in partnership with the patient, with a shared understanding of the rationale for treatment, its limitations and the risk of adverse events.

There is a relative lack of randomised controlled trials in the treatment of NTM-PD. The majority of evidence is provided by cases series, and for less common species there is no evidence to guide treatment. The aforementioned ATS/IDSA statement on NTM-PD [8] gave recommendations on treatment of major NTM species that have been widely adopted, and an updated guideline in association with the European Respiratory Society and European Society of Clinical Microbiology and Infectious Diseases is in preparation. Recommendations have also recently been published by the British Thoracic Society and several other specialist societies have also issued guidelines [161-163].

\section{M. avium complex}

The standard of care for the treatment of MAC is a macrolide-containing regimen, typically in combination with rifampicin and ethambutol, although reported outcomes vary. The efficacy of this combination was demonstrated by a large retrospective series which found it achieved maintained culture conversion in $82 \%$ of 180 subjects with macrolide susceptible nodular bronchiectatic disease, although subsequent relapse was seen in $48 \%$ [164]. Outcomes in a more heterogeneous population were reported in a meta-analysis encompassing 1462 subjects across 16 studies (not including the above), finding a more modest overall culture conversion rate of $60 \%$ [165]. The use of a range of companion drugs and dosing regimens, the varying inclusion of fibrocavitary and macrolide resistant disease and exclusion of patients not completing treatment in the former study may go some way to explaining this discrepancy [166].

The treatment of refractory and macrolide resistant disease remains challenging. For refractory MAC lung disease, two recent studies of inhaled liposome encapsulated amikacin have shown improved

\begin{tabular}{|l|}
\hline \multicolumn{1}{|c|}{ Host factors } \\
\hline Age \\
Increasing risk of intolerance \\
and adverse events \\
Comorbidities \\
Drug intolerances \\
Consider dose reduction or \\
thrice-weekly regimens \\
Consider interactions with \\
other drugs, e.g. azoles \\
Patient wishes \\
Aim of treatment \\
Aiming for cure or disease \\
control?
\end{tabular}

\begin{tabular}{|l|}
\hline Disease severity \\
\hline Radiological \\
Fibrocavitary disease \\
Clinical \\
Weight loss, fever, \\
haemoptysis, respiratory \\
failure \\
Biochemical markers \\
Microbiological \\
Smear positivity \\
\end{tabular}
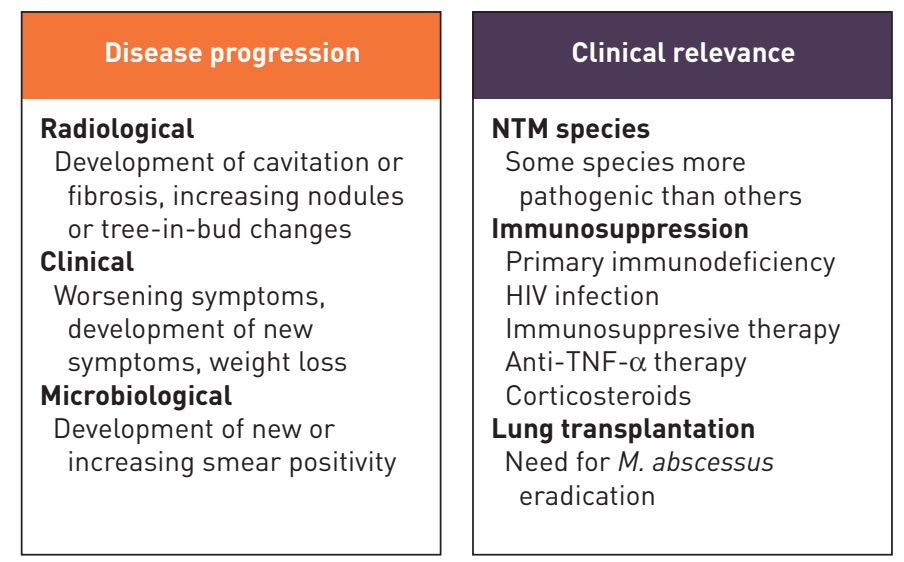

FIGURE 3 Factors to consider when deciding on the initiation of treatment for pulmonary nontuberculous mycobacterial (NTM) disease. TNF: tumour necrosis factor. 
microbiological outcomes compared with continuation of standard multidrug therapy alone [141, 145]. For macrolide resistant MAC disease, two studies have shown that a combination of parenteral antibiotic administration and surgical resection of involved lung is associated with favourable microbiological outcome $[167,168]$, while antibiotic therapy was associated with treatment failure and high mortality. A study using combinations of rifabutin, clofazimine, linezolid and moxifloxacin reported similarly poor sustained culture conversion in only $18 \%$ of patients [169].

\section{M. abscessus complex}

The M. abscessus complex is comprised of three subspecies: subsp. abscessus, subsp. massiliense and subsp. bolletii. Subspecies determination of $M$. abscessus complex isolates is necessary to guide therapy, as two subspecies (subsp. abscessus and subsp. bolletii) have an active inducible macrolide resistance gene (erm41) and are macrolide resistant, while subsp. massiliense has an inactive erm41 gene and is macrolide susceptible. It is imperative that $M$. abscessus complex isolates should be identified to subspecies and that macrolide susceptibility is also determined phenotypically in all M. abscessus complex isolates.

Due to the intrinsic drug resistance of the M. abscessus complex, treatment is difficult and regimens typically require large numbers of agents with an induction phase of parenteral therapy lasting several weeks to possibly months. A series of 41 subjects treated with a macrolide plus prolonged parenteral therapy with amikacin, with or without imipenem or cefoxitin (median 230 days), achieved sputum conversion in $81 \%$ with a $12 \%$ relapse rate during follow-up [170]. Another retrospective study found a conversion rate of only $48 \%$ using combinations of amikacin, imipenem and a macrolide plus surgery where indicated [171].

As mentioned previously, a strong link has been observed between macrolide resistance in $M$. abscessus complex and treatment failure. A meta-analysis of treatment outcomes revealed that in contrast to the disappointing sustained sputum conversion rates of undifferentiated M. abscessus complex (59\%), studies reporting the specific treatment response in subsp. massiliense reported sputum conversion rates of up to $79 \%$. In contrast the conversion rate seen in subsp. abscessus was very poor (35\%) [172]. While this offers the hope that less intensive treatment regimens may be used in subsp. massiliense infection [173], since the majority of isolates belong to subsp. abscessus there is a pressing need for better treatment regimens in this group.

The treatment of refractory or macrolide resistant disease also remains challenging. Tigecycline has in vitro bactericidal activity [146] and treatment was associated with a clinical response in $44 \%$ of patients in a small series but there are no data on microbiological outcomes [174]. Clofazimine-containing regimens have been reported to reduce semiquantative culture scores and achieved culture conversion in $24-50 \%$ $[175,176]$.

\section{New approaches to treatment \\ Oxazolidinones}

The oxazolidinone linezolid has in vitro activity against many NTM $[177,178]$. There are several reports of its successful use in NTM disease [179-186], including a series of 16 patients with disseminated disease due to anti-IFN- $\gamma$ antibodies where a $50 \%$ response rate was seen with linezolid-containing regimens [187]. Side-effects were reported in $45 \%$ of subjects in the largest case series to date [188]. The newer agent tedizolid shows greater in vitro activity [189-191], and one report suggests it is better tolerated [192], although there is only one case report to date of successful clinical use [193].

\section{Inhaled amikacin}

Delivering amikacin through inhalation offers the advantage of limiting systemic toxicity and achieving high drug levels at the site of disease. Data from a retrospective study of 20 subjects with refractory MAC and $M$. abscessus disease found the addition of inhaled amikacin achieved culture conversion in $25 \%$ and an improvement in symptoms in 45\% [194]. More recently, a randomised controlled trial of the addition of ALIS to an existing regimen for refractory MAC and M. abscessus disease found that more patients receiving ALIS achieved $>1$ negative culture by day 84 (32\% versus $9 \%$ ), which was maintained until day 168 in $79 \%$ in those who converted to negative [145]. A greater response was seen in MAC, and a subsequent phase 3 trial found a significantly higher 6-month culture conversion rate with the addition of ALIS (29\%) versus placebo (8.9\%) to guideline based therapy [141]. ALIS has now been approved for use for this indication in the USA. A trial in M. abscessus subsp. abscessus is ongoing (NCT03038178).

\section{Antituberculous drugs}

The new agent bedaquiline was developed for multidrug-resistant TB (MDR-TB) and is bacteriostatic against a range of NTM, including M. abscessus [195] and MAC [196-198]. However, several species, 
notably M. xenopi, show resistance conferred by a mutation in the atpE gene [198, 199], and emergence of resistance conferred by mutation in the $m m p T 5$ gene has been reported in $M$. intracellulare [200]. There has been only one report of its use in NTM-PD, where in 10 subjects with refractory disease receiving 6 months of treatment a radiological improvement was seen in $40 \%$ and an improvement in semiquantiative culture scores was seen in 50\%, but none achieved sustained culture conversion [201]. Another new agent for MDR-TB, delamanid, shows in vitro activity against MAC [202]; however, there are no reports regarding its clinical efficacy.

Mefloquine is an antimalarial agent which has antimycobacterial activity [203] and shows in vitro and in vivo activity against $M$. avium [204]. One case report describes its successful use as part of a regimen in refractory MAC disease [183] but its clinical efficacy was unclear in another report [205]. The neuroleptic thioridazine also has antimycobacterial activity, has shown in vitro activity against $M$. avium and accumulates in high concentrations within macrophages, but is limited by neurological and cardiac toxicity [206] and there are no reports of its clinical use in NTM-PD.

\section{Drugs in development}

The ketolide antibiotic solithromycin shows activity against $M$. avium and has the advantage of being resistant to erythromycin resistance methylases (such as that encoded by the erm(41) gene) [207], although it displays significant hepatotoxicity [208].

The search for drugs to treat MDR-TB may also identify further agents with useful activity against NTM. A study which screened 129 compounds previously identified as active against M. tuberculosis identified 10 compounds showing activity against NTM. These included three oxazolidinones and one macrolide, but further diverse possible targets were identified including a cytoskeletal protein (FtsZ) DNA gyrase (GyrB), dihydropholate reductase (DHFR), RNA polymerase, the ABC transporter and a mycolic acid transporter (MmpL3) [209]. The latter has been repeatedly identified as a potential therapeutic target [210] and several agents targeting MmpL3 have been shown to display in vivo activity against NTM [211, 212].

\section{Beta-lactamase inhibition}

Overcoming antimicrobial resistance mechanisms may be another route to expanding the available armamentarium. Deficiency of the beta-lactamase $\mathrm{Bla}_{\mathrm{Mab}}$ renders $M$. abscessus susceptible to amoxicillin and ceftaroline, and allows synergy between imipenem and amikacin, which in combination displayed bactericidal activity [213]. Addition of the beta-lactamase inhibitor avibactam increased the intracellular activity of ceftaroline in this study, and it has also been shown to increase the activity of imipenem [214] and carbapenems including ertapenem [215]. The commercially available combination ceftazidime/ avibactam also shows in vitro activity against MAC [216].

\section{Immunomodulation}

Another treatment approach is to utilise the immune response to fight infection. The largest trial of such treatment looked at immunotherapy with $M$. vaccae in a randomised controlled trial [217] and found no benefit. Case reports have suggested benefit from adjuvant IFN- $\gamma$ (usually in the context of immunodeficiency) [218-222], but data from clinical trials in NTM-PD are limited and inconsistent. The addition of inhaled IFN- $\gamma$ showed no benefit in one trial [223], but in another parenteral therapy was associated with a significantly higher response to treatment (83\% versus 36\%) and higher rate of sputum conversion ( $92 \%$ versus 50\%), although the baseline drug regimen was unconventional [224]. A recent case report found no benefit in the supplementation of IFN- $\gamma$ to two subjects with impaired baseline IFN- $\gamma$ responses [79]. Two reports have also found benefit from the addition of subcutaneous or inhaled GM-CSF in CF and M. abscessus infection $[225,226]$, potentially through activation of macrophages and improved cellular immunity. Nitric oxide plays a key bactericidal and bacteriostatic role in the host defence against mycobacteria [227], and one case report of two subjects with CF demonstrated a marked fall in $M$. abscessus sputum load during treatment with inhaled nitric oxide [228]. One interesting report showed a clinical and microbiological response to the addition of thalidomide in a subject with disseminated MAC [229]. The authors suggest that selective inhibition of TNF- $\alpha$ and amelioration of immune-mediated pathology was responsible.

\section{Summary}

Despite an increasing body of research and international collaboration, fundamental questions remain unanswered in NTM-PD. The prevalence is increasing but the reason for this is unclear, and the lack of notification in most areas complicates even estimating the exact disease prevalence. A concerning finding of recent studies has been the evidence of between-person transmission of NTM, although as the route by which infection is acquired (or spread) is uncertain it is not possible to formulate evidence-based 
recommendations for infection control. There is an urgent need for better understanding of these factors, particularly in the context of CF.

No single unifying host factor has been identified as conferring susceptibility and it seems likely that a variety of different pathways increase an individual's risk of infection, which combined with environmental factors culminates in the development of NTM-PD. Mutations in CFTR have been consistently linked with disease, and the results provided by exome sequencing regarding variants in cilia, immune and connective tissue associated genes also provide a useful avenue for further research.

Once NTM-PD is diagnosed the decision to treat is challenging and work in this area should focus on the development of markers of disease activity and predictors of progression, in order to better target who to treat and who to observe. Treatment outcomes remain suboptimal and it is disappointing that more than 10 years have elapsed since the ATS guidelines were published in 2007, but treatment for MAC has not progressed, with failure rates of $18-40 \%$. The management of $M$. abscessus has been informed by our increasing understanding of its taxonomy, including the discovery of inducible macrolide resistance, and reports of multidrug regimens with prolonged parental therapy have demonstrated the ability to achieve maintained sputum conversion, although outcomes in macrolide resistant disease remain dismal.

In refractory disease the development of ALIS represents the first agent specifically licensed for use in NTM-PD, the result of the collaborative effort of more than 100 centres across the world. Other agents such as tigecycline, oxazolidinones and bedaquiline show promising in vitro efficacy and have already entered clinical use, but the evidence base is lacking at present. However, while recent studies have rightly focused on the treatment of refractory disease, there is also the need for better first-line treatment options.

Conflict of interest: S. Cowman has nothing to disclose. J. van Ingen has nothing to disclose. D.E. Griffith reports grants, personal fees for consultancy and non-financial support from Insmed Inc., outside the submitted work. M.R. Loebinger reports personal fees for advisory board work and lecturing from Insmed, personal fees for advisory board work from Savara, outside the submitted work.

\section{References}

1 American Thoracic Society. Diagnosis and treatment of disease caused by nontuberculous mycobacteria. Am Rev Respir Dis 1990; 142: 940-953.

2 Falkinham J III. Ecology of nontuberculous mycobacteria-where do human infections come from? Semin Respir Crit Care Med 2013; 34: 095-102.

3 Feldman WH, Hutchinson D. Pathogenicity studies of tubercle bacilli, type avium, from a human infection. Am $J$ Pathol 1948; 24: 696.

4 Tortoli E. Clinical manifestations of nontuberculous mycobacteria infections. Clin Microbiol Infect 2009; 15: 906-910.

5 Euzeby JP. List of bacterial names with standing in nomenclature: a folder available on the internet. Int $J$ Syst Bacteriol 1997; 47: 590-592.

6 van Ingen J. Diagnosis of nontuberculous mycobacterial infections. Semin Respir Crit Care Med 2013; 34: 103-109.

7 Brown-Elliott BA, Wallace RJ. Clinical and taxonomic status of pathogenic nonpigmented or late-pigmenting rapidly growing mycobacteria. Clin Microbiol Rev 2002; 15: 716-746.

8 Griffith DE, Aksamit T, Brown-Elliott BA, et al. An Official ATS/IDSA Statement: diagnosis, treatment, and prevention of nontuberculous mycobacterial diseases. Am J Respir Crit Care Med 2007; 175: 367-416.

9 Adjemian J, Olivier KN, Seitz AE, et al. Prevalence of nontuberculous mycobacterial lung disease in U.S. Medicare beneficiaries. Am J Respir Crit Care Med 2012; 185: 881-886.

10 Prevots DR, Shaw PA, Strickland D, et al. Nontuberculous mycobacterial lung disease prevalence at four integrated health care delivery systems. Am J Respir Crit Care Med 2010; 182: 970-976.

11 Morimoto K, Iwai K, Uchimura K, et al. A steady increase in nontuberculous mycobacteriosis mortality and estimated prevalence in Japan. Ann Am Thorac Soc 2014; 11: 1-8.

12 Zweijpfenning SMH, Ingen JV, Hoefsloot W. Geographic distribution of nontuberculous mycobacteria isolated from clinical specimens: a systematic review. Semin Respir Crit Care Med 2018; 39: 336-342.

13 Hoefsloot W, van Ingen J, Andréjak C, et al. The geographic diversity of nontuberculous mycobacteria isolated from pulmonary samples: an NTM-NET collaborative study. Eur Respir J 2013; 42: 1604-1613.

14 Spaulding AB, Lai YL, Zelazny AM, et al. Geographic distribution of nontuberculous mycobacterial species identified among clinical isolates in the United States, 2009-2013. Ann Am Thorac Soc 2017; 14: 1655-1661.

15 Morimoto K, Hasegawa N, Izumi K, et al. A laboratory-based analysis of nontuberculous mycobacterial lung disease in Japan from 2012 to 2013. Ann Am Thorac Soc 2017; 14: 49-56.

16 Marras TK, Chedore P, Ying AM, et al. Isolation prevalence of pulmonary non-tuberculous mycobacteria in Ontario, 1997-2003. Thorax 2007; 62: 661-666.

17 Moore JE, Kruijshaar ME, Ormerod LP, et al. Increasing reports of non-tuberculous mycobacteria in England, Wales and Northern Ireland, 1995-2006. BMC Public Health 2010; 10: 612.

18 van Ingen J, Hoefsloot W, Dekhuijzen PNR, et al. The changing pattern of clinical Mycobacterium avium isolation in the Netherlands. Int J Tuberc Lung Dis 2010; 14: 1176-1180.

19 Martín-Casabona N, Bahrmand AR, Bennedsen J, et al. Non-tuberculous mycobacteria: patterns of isolation. A multi-country retrospective survey. Int J Tuberc Lung Dis 2004; 8: 1186-1193.

20 Shah NM, Davidson JA, Anderson LF, et al. Pulmonary Mycobacterium avium-intracellulare is the main driver of the rise in non-tuberculous mycobacteria incidence in England, Wales and Northern Ireland, 2007-2012. BMC Infect Dis 2016; 16: 195. 
Thomson R, Donnan E, Konstantinos A. Notification of nontuberculous mycobacteria: an Australian perspective. Ann Am Thorac Soc 2017; 14: 318-323.

Ide S, Nakamura S, Yamamoto Y, et al. Epidemiology and clinical features of pulmonary nontuberculous mycobacteriosis in Nagasaki, Japan. PLoS ONE 2015; 10: e0128304.

Ding LW, Lai C-C, Lee L-N, et al. Disease caused by non-tuberculous mycobacteria in a university hospital in Taiwan, 1997-2003. Epidemiol Infect 2006; 134: 1060-1067.

Park YS, Lee CH, Lee S-M, et al. Rapid increase of non-tuberculous mycobacterial lung diseases at a tertiary referral hospital in South Korea. Int J Tuberc Lung Dis 2010; 14: 1069-1071.

Russell CD, Claxton P, Doig C, et al. Non-tuberculous mycobacteria: a retrospective review of Scottish isolates from 2000 to 2010. Thorax 2014; 69: 593-595.

Hernández-Garduño E, Rodrigues M, Elwood RK. The incidence of pulmonary non-tuberculous mycobacteria in British Columbia, Canada. Int J Tuberc Lung Dis 2009; 13: 1086-1093.

Vinnard C, Longworth S, Mezochow A, et al. Deaths related to nontuberculous mycobacterial infections in the United States, 1999-2014. Ann Am Thorac Soc 2016; 13: 1951-1955.

Khan K, Wang J, Marras TK. Nontuberculous mycobacterial sensitization in the United States. Am J Respir Crit Care Med 2007; 176: 306-313.

Aitken ML, Limaye A, Pottinger P, et al. Respiratory outbreak of Mycobacterium abscessus subspecies massiliense in a lung transplant and cystic fibrosis center. Am J Respir Crit Care Med 2012; 185: 231-232.

Bryant JM, Grogono DM, Greaves D, et al. Whole-genome sequencing to identify transmission of Mycobacterium abscessus between patients with cystic fibrosis: a retrospective cohort study. Lancet 2013; 381: $1551-1560$.

Tettelin H, Davidson RM, Agrawal S, et al. High-level relatedness among Mycobacterium abscessus subsp. massiliense strains from widely separated outbreaks. Emerging Infect Dis 2014; 20: 364-371.

Bryant JM, Grogono DM, Rodriguez-Rincon D, et al. Emergence and spread of a human-transmissible multidrug-resistant nontuberculous mycobacterium. Science 2016; 354: 751-757.

Malcolm KC, Caceres SM, Honda JR, et al. Mycobacterium abscessus displays fitness for fomite transmission. Appl Environ Microbiol 2017; 83: e00562-17.

Foto RA, Olivier KN, Saiman L, et al. US Cystic Fibrosis Foundation and European Cystic Fibrosis Society consensus recommendations for the management of non-tuberculous mycobacteria in individuals with cystic fibrosis. Thorax 2016; 71: Suppl. 1, i1-i22.

Adjemian J, Olivier KN, Seitz AE, et al. Spatial clusters of nontuberculous mycobacterial lung disease in the United States. Am J Respir Crit Care Med 2012; 186: 553-558.

Prevots DR, Adjemian J, Fernandez AG, et al. Environmental risks for nontuberculous mycobacteria. Individual exposures and climatic factors in the cystic fibrosis population. Ann Am Thorac Soc 2014; 11: 1032-1038.

Falkinham JO. Nontuberculous mycobacteria from household plumbing of patients with nontuberculous mycobacteria disease. Emerging Infect Dis 2011; 17: 419-424.

Thomson R, Tolson C, Carter R, et al. Isolation of nontuberculous mycobacteria (NTM) from household water and shower aerosols in patients with pulmonary disease caused by NTM. J Clin Microbiol 2013; 51: 3006-3011.

Lipner EM, Knox D, French J, et al. A geospatial epidemiologic analysis of nontuberculous mycobacterial infection: an ecological study in Colorado. Ann Am Thorac Soc 2017; 14: 1523-1532.

De Groote MA, Pace NR, Fulton K, et al. Relationships between Mycobacterium isolates from patients with pulmonary mycobacterial infection and potting soils. Appl Environ Microbiol 2006; 72: 7602-7606.

Fujita K, Ito Y, Hirai T, et al. Genetic relatedness of Mycobacterium avium-intracellulare complex isolates from patients with pulmonary MAC disease and their residential soils. Clin Microbiol Infect 2013; 19: 537-541.

Reed C, Reyn von CF, Chamblee S, et al. Environmental risk factors for infection with Mycobacterium avium complex. Am J Epidemiol 2006; 164: 32-40.

Hamada S, Ito Y, Hirai T, et al. Impact of industrial structure and soil exposure on the regional variations in pulmonary nontuberculous mycobacterial disease prevalence. Int J Mycobacteriol 2016; 5: 170-176.

Honda JR, Virdi R, Chan ED. Global environmental nontuberculous mycobacteria and their contemporaneous man-made and natural niches. Front Microbiol 2018; 9: 2029.

Wickremasinghe M, Ozerovitch LJ, Davies G, et al. Non-tuberculous mycobacteria in patients with bronchiectasis. Thorax 2005; 60: 1045-1051.

Fowler SJ, French J, Screaton NJ, et al. Nontuberculous mycobacteria in bronchiectasis: prevalence and patient characteristics. Eur Respir J 2006; 28: 1204-1210.

Huang C-T, Tsai Y-J, Wu H-D, et al. Impact of non-tuberculous mycobacteria on pulmonary function decline in chronic obstructive pulmonary disease. Int J Tuberc Lung Dis 2012; 16: 539-545.

Griffith DE, Girard WM, Wallace RJ. Clinical features of pulmonary disease caused by rapidly growing mycobacteria. An analysis of 154 patients. Am Rev Respir Dis 1993; 147: 1271-1278.

Hojo M, Iikura M, Hirano S, et al. Increased risk of nontuberculous mycobacterial infection in asthmatic patients using long-term inhaled corticosteroid therapy. Respirology 2011; 17: 185-190.

Martiniano SL, Nick JA, Daley CL. Nontuberculous mycobacterial infections in cystic fibrosis. Clin Chest Med 2016; 37: 83-96.

Ripoll F, Pasek S, Schenowitz C, et al. Non mycobacterial virulence genes in the genome of the emerging pathogen Mycobacterium abscessus. PLoS ONE 2009; 4: e5660.

Miranda-CasoLuengo AA, Staunton PM, Dinan AM, et al. Functional characterization of the Mycobacterium abscessus genome coupled with condition specific transcriptomics reveals conserved molecular strategies for host adaptation and persistence. BMC Genomics 2016; 17: 553.

Noone PG, Leigh MW, Sannuti A, et al. Primary ciliary dyskinesia: diagnostic and phenotypic features. Am J Respir Crit Care Med 2004; 169: 459-467.

Chang H, Adjemian J, Dell SDM, et al. Prevalence of airway microbial flora in primary ciliary dyskinesia. Am J Respir Crit Care Med 2015; 191: A1798.

Fowler CJ, Olivier KN, Leung JM, et al. Abnormal nasal nitric oxide production, ciliary beat frequency, and Toll-like receptor response in pulmonary nontuberculous mycobacterial disease epithelium. Am J Respir Crit Care Med 2013; 187: 1374-1381. 
Reich JM. Mycobacterium avium complex pulmonary disease presenting as an isolated lingular or middle lobe pattern. The Lady Windermere syndrome. Chest 1992; 101: 1605-1609.

Prince DS, Peterson DD, Steiner RM, et al. Infection with Mycobacterium avium complex in patients without predisposing conditions. N Engl J Med 1989; 321: 863-868.

Kim RD, Greenberg DE, Ehrmantraut ME, et al. Pulmonary nontuberculous mycobacterial disease: prospective study of a distinct preexisting syndrome. Am J Respir Crit Care Med 2008; 178: 1066-1074.

Iseman MD, Buschman DL, Ackerson LM. Pectus excavatum and scoliosis. Thoracic anomalies associated with pulmonary disease caused by Mycobacterium avium complex. Am Rev Respir Dis 1991; 144: 914-916.

Sexton P, Harrison AC. Susceptibility to nontuberculous mycobacterial lung disease. Eur Respir J 2008; 31 : $1322-1333$.

Chan ED, Bai X, Kartalija M, et al. Host immune response to rapidly growing mycobacteria, an emerging cause of chronic lung disease. Am J Respir Cell Mol Biol 2010; 43: 387-393.

Kartalija M, Ovrutsky AR, Bryan CL, et al. Patients with nontuberculous mycobacterial lung disease exhibit unique body and immune phenotypes. Am J Respir Crit Care Med 2013; 187: 197-205.

Winthrop KL, Chang E, Yamashita S, et al. Nontuberculous mycobacteria infections and anti-tumor necrosis factor-alpha therapy. Emerging Infect Dis 2009; 15: 1556-1561.

Liao T-L, Lin C-F, Chen Y-M, et al. Risk factors and outcomes of nontuberculous mycobacterial disease among rheumatoid arthritis patients: a case-control study in a TB endemic area. Sci Rep 2016; 6: 29443. non-tuberculous mycobacteriosis. Thorax 2013; 68: 256-262.

Liu VX, Winthrop KL, Lu Y, et al. Association between inhaled corticosteroid use and pulmonary nontuberculous mycobacterial infection. Ann Am Thorac Soc 2018; 15: 1169-1176.

Brode SK, Campitelli MA, Kwong JC, et al. The risk of mycobacterial infections associated with inhaled corticosteroid use. Eur Respir J 2017; 50: 1700037.

Havlik JA, Horsburgh CR, Metchock B, et al. Disseminated Mycobacterium avium complex infection: clinical identification and epidemiologic trends. J Infect Dis 1992; 165: 577-580.

Rosain J, Kong X-F, Martinez-Barricarte R, et al. Mendelian susceptibility to mycobacterial disease: 2014-2018 update. Immunol Cell Biol 2019; 97: 360-367.

Hsu AP, McReynolds LJ, Holland SM. GATA2 deficiency. Curr Opin Allergy Clin Immunol 2015; 15: 104-109.

Browne SK, Burbelo PD, Chetchotisakd P, et al. Adult-onset immunodeficiency in Thailand and Taiwan. $N$ Engl $J$ Med 2012; 367: 725-734.

Kim K, Waterer G, Thomson R, et al. Levels of anti-cytokine antibodies may be elevated in patients with pulmonary disease associated with non-tuberculous mycobacteria. Cytokine 2014; 66: 160-163.

Greinert U, Schlaak M, Rüsch-Gerdes S, et al. Low in vitro production of interferon-gamma and tumor necrosis factor-alpha in HIV-seronegative patients with pulmonary disease caused by nontuberculous mycobacteria. J Clin Immunol 2000; 20: 445-452.

Vankayalapati R, Wizel B, Samten B, et al. Cytokine profiles in immunocompetent persons infected with Mycobacterium avium complex. J Infect Dis 2001; 183: 478-484.

Safdar A, Armstrong D, Murray HW. A novel defect in interferon-gamma secretion in patients with refractory nontuberculous pulmonary mycobacteriosis. Ann Intern Med 2003; 138: 521.

Ryu YJ, Kim EJ, Lee S-H, et al. Impaired expression of Toll-like receptor 2 in nontuberculous mycobacterial lung disease. Eur Respir J 2007; 30: 736-742.

Kwon Y-S, Kim EJ, Lee S-H, et al. Decreased cytokine production in patients with nontuberculous mycobacterial lung disease. Lung 2007; 185: 337-341.

Lim A, Allison C, Price P, et al. Susceptibility to pulmonary disease due to Mycobacterium avium-intracellulare complex may reflect low IL-17 and high IL-10 responses rather than Th1 deficiency. Clin Immunol 2010; 137: 296-302.

Rae W, Gao Y, Eren E, et al. Differential impairment of interferon- $\gamma$ responses in two cases of pulmonary nontuberculous mycobacterial disease. Case Reports Immunol 2016; 2016: 9165641-9165644.

Becker KL, van Ingen J, Oever Ten J, et al. Deficient interleukin-17 production in response to Mycobacterium abscessus in cystic fibrosis. Eur Respir J 2016; 47: 990-993.

Shu C-C, Wang J-Y, Wu M-F, et al. Attenuation of lymphocyte immune responses during Mycobacterium avium complex-induced lung disease due to increasing expression of programmed death-1 on lymphocytes. Sci Rep 2017; 7: 42004.

Shu C-C, Wang J-Y, Wu M-F, et al. Interleukin 23/interleukin 17 axis activated by Mycobacterium avium complex (MAC) is attenuated in patients with MAC-lung disease. Tuberculosis (Edinb) 2018; 110: 7-14.

Lutzky VP, Ratnatunga CN, Smith DJ, et al. Anomalies in T cell function are associated with individuals at risk of Mycobacterium abscessus complex infection. Front Immunol 2018; 9: 1319.

Infect 2007; 9: 623-628

Redford PS, Murray PJ, O'Garra A. The role of IL-10 in immune regulation during M. tuberculosis infection. Mucosal Immunol 2011; 4: 261-270.

Ovrutsky AR, Merkel PA, Schonteich E, et al. Patients with non-tuberculous mycobacterial lung disease have elevated transforming growth factor-beta following ex vivo stimulation of blood with live Mycobacterium intracellulare. Scand J Infect Dis 2013; 45: 711-714.

Torrado E, Cooper AM. IL-17 and Th17 cells in tuberculosis. Cytokine Growth Factor Rev 2010; 21: 455-462.

Kim S-Y, Koh W-J, Kim YH, et al. Importance of reciprocal balance of T cell immunity in Mycobacterium abscessus complex lung disease. PLoS ONE 2014; 9: e109941.

Jo E-K, Yang C-S, Choi $\mathrm{CH}$, et al. Intracellular signalling cascades regulating innate immune responses to mycobacteria: branching out from Toll-like receptors. Cell Microbiol 2007; 9: 1087-1098.

Cowman SA, Jacob J, Hansell DM, et al. Whole blood gene expression in pulmonary non-tuberculous mycobacterial infection. Am J Respir Cell Mol Bio 2017; 58: 510-518.

Garra A, Redford PS, McNab FW, et al. The immune response in tuberculosis. Annu Rev Immunol 2013; 31 475-527. 
Abel L, Fellay J, Haas DW, et al. Genetics of human susceptibility to active and latent tuberculosis: present knowledge and future perspectives. Lancet Infect Dis 2018; 18: e64-e75.

Colombo RE. Familial clustering of pulmonary nontuberculous mycobacterial disease. Chest 2010; 137: 629-634.

Huang JH, Oefner PJ, Adi V, et al. Analyses of the NRAMP1 and IFN-gammaR1 genes in women with Mycobacterium avium-intracellulare pulmonary disease. Am J Respir Crit Care Med 1998; 157: 377-381.

Gelder CM, Hart KW, Williams OM, et al. Vitamin D receptor gene polymorphisms and susceptibility to Mycobacterium malmoense pulmonary disease. J Infect Dis 2000; 181: 2099-2102.

Tanaka E, Kimoto T, Matsumoto H, et al. Familial pulmonary Mycobacterium avium complex disease. Am J Respir Crit Care Med 2000; 161: 1643-1647.

Koh W-J. NRAMP1 gene polymorphism and susceptibility to nontuberculous mycobacterial lung diseases. Chest 2005; 128: 94-101.

Kim JS, Tanaka N, Newell JD, et al. Nontuberculous mycobacterial infection: CT scan findings, genotype, and treatment responsiveness. Chest 2005; 128: 3863-3869.

Ryu YJ, Kim EJ, Koh W-J, et al. Toll-like receptor 2 polymorphisms and nontuberculous mycobacterial lung diseases. Clin Vaccine Immunol 2006; 13: 818-819.

Ziedalski TM, Kao PN, Henig NR, et al. Prospective analysis of cystic fibrosis transmembrane regulator mutations in adults with bronchiectasis or pulmonary nontuberculous mycobacterial infection. Chest 2006; 130: 995-1002.

Mai HN, Hijikata M, Inoue Y, et al. Pulmonary Mycobacterium avium complex infection associated with the IVS8-T5 allele of the CFTR gene. Int J Tuberc Lung Dis 2007; 11: 808-813.

Tanaka G, Shojima J, Matsushita I, et al. Pulmonary Mycobacterium avium complex infection: association with NRAMP1 polymorphisms. Eur Respir J 2007; 30: 90-96.

Park HY, Kwon Y-S, Ki C-S, et al. Interleukin-12 receptor betal polymorphisms and nontuberculous mycobacterial lung diseases. Lung 2008; 186: 241.

Park S, Kim EJ, Lee S-H, et al. Vitamin D-receptor polymorphisms and non-tuberculous mycobacterial lung disease in Korean patients. Int J Tuberc Lung Dis 2008; 12: 698-700.

Yim J-J, Kim HJ, Kwon OJ, et al. Association between microsatellite polymorphisms in intron II of the human Toll-like receptor 2 gene and nontuberculous mycobacterial lung disease in a Korean population. Hum Immunol 2008; 69: 572-576.

Matsuyama M, Miura Y, Kiwamoto T, et al. A case of familial pulmonary Mycobacterium avium complex disease. Intern Med 2010; 49: 949-953.

Affandi JS, Hendry S, Waterer G, et al. Searching for an immunogenetic factor that will illuminate susceptibility to non-tuberculous mycobacterial disease. Hum Immunol 2013; 74: 1382-1385.

Jang M-A, Kim S-Y, Jeong B-H, et al. Association of CFTR gene variants with nontuberculous mycobacterial lung disease in a Korean population with a low prevalence of cystic fibrosis. J Hum Genet 2013; 58: 298-303.

Farnia P, Ghanavi J, Saif S, et al. Association of interferon- $\gamma$ receptor-1 gene polymorphism with nontuberculous mycobacterial lung infection among Iranian patients with pulmonary disease. Am J Trop Med Hyg 2017; 97: $57-61$.

Szymanski EP, Leung JM, Fowler CJ, et al. Pulmonary nontuberculous mycobacterial infection. A multisystem, multigenic disease. Am J Respir Crit Care Med 2015; 19: 618-628.

Halstrom S, Thomson R, Goullee H, et al. Susceptibility to non-tuberculous mycobacterial disease is influenced by rs1518111 in IL10. Hum Immunol 2017; 78: 391-393.

Becker KL, Arts P, Jaeger M, et al. MST1R mutation as a genetic cause of Lady Windermere syndrome. Eur Respir J 2017; 49: 1601478.

Chen F, Szymanski EP, Olivier KN, et al. Whole-exome sequencing identifies the 6q12-q16 linkage region and a candidate gene, TTK, for pulmonary nontuberculous mycobacterial disease. Am J Respir Crit Care Med 2017; 196: 1599-1604.

4 Takahashi M, Ishizaka A, Nakamura $\mathrm{H}$, et al. Specific HLA in pulmonary MAC infection in a Japanese population. Am J Respir Crit Care Med 2000; 162: 316-318.

o K, Yamazaki Y, Hanaoka M, et al. Analysis of HLA antigens in Mycobacterium avium-intracellulare pulmonary infection. Am J Respir Crit Care Med 2000; 161: 1368-1371.

Chakraborty AK, Damle PB, Davidson PT, et al. Disease due to Mycobacterium intracellulare: its possible association with human leukocyte antigens. Rev Infect Dis 1981; 3: 1060-1063.

Chan ED, Kaminska AM, Gill W, et al. Alpha-1-antitrypsin (AAT) anomalies are associated with lung disease due to rapidly growing mycobacteria and AAT inhibits Mycobacterium abscessus infection of macrophages. Scand J Infect Dis 2007; 39: 690-696. Med 2018; 39: 343-350.

Erasmus JJ, McAdams HP, Farrell MA, et al. Pulmonary nontuberculous mycobacterial infection: radiologic manifestations. Radiographics 1999; 19: 1487-1505.

Ellis SM, Hansell DM. Imaging of non-tuberculous (atypical) mycobacterial pulmonary infection. Clin Radiol 2002; 57: 661-669.

Pennings LJ, Zweijpfenning S, Ruth MM, et al. Mycobacterium avium complex bacteria remain viable in sputum during storage and refrigeration. Diagn Microbiol Infect Dis 2018; 92: 309-310.

Tanaka E, Amitani R, Niimi A, et al. Yield of computed tomography and bronchoscopy for the diagnosis of Mycobacterium avium complex pulmonary disease. Am J Respir Crit Care Med 1997; 155: 2041-2046.

Sugihara E, Hirota N, Niizeki T, et al. Usefulness of bronchial lavage for the diagnosis of pulmonary disease caused by Mycobacterium avium-intracellulare complex (MAC) infection. J Infect Chemother 2003; 9: 328-332. van Ingen J. Microbiological diagnosis of nontuberculous mycobacterial pulmonary disease. Clin Chest Med 2015; 36: 43-54.

van Ingen J, Turenne CY, Tortoli E, et al. A definition of the Mycobacterium avium complex for taxonomical and clinical purposes, a review. Int J Syst Evol Microbiol 2018; 68: 3666-3677.

Alcaide F, Amlerová J, Bou G, et al. How to: identify non-tuberculous Mycobacterium species using MALDI-TOF mass spectrometry. Clin Microbiol Infect 2018; 24: 599-603. 
van Ingen J, Boeree MJ, van Soolingen D, et al. Are phylogenetic position, virulence, drug susceptibility and in vivo response to treatment in mycobacteria interrelated? Infect Genet Evol 2012; 12: 832-837.

Kim K, Lee H, Lee M-K, et al. Development and application of multiprobe real-time PCR method targeting the hsp65 gene for differentiation of Mycobacterium species from isolates and sputum specimens. J Clin Microbiol 2010; 48: 3073-3080

Tran AC, Halse TA, Escuyer VE, et al. Detection of Mycobacterium avium complex DNA directly in clinica respiratory specimens: opportunities for improved turn-around time and cost savings. Diagn Microbiol Infect Dis 2014; 79: 43-48.

Wu T-L, Chia J-H, Kuo A-J, et al. Rapid identification of mycobacteria from smear-positive sputum samples by nested PCR-restriction fragment length polymorphism analysis. J Clin Microbiol 2008; 46: 3591-3594.

Scoleri GP, Choo JM, Leong LEX, et al. Culture-independent detection of nontuberculous mycobacteria in clinical respiratory samples. J Clin Microbiol 2016; 54: 2395-2398.

im J-U, Ryu D-S, Cha C-H, et al. Paradigm for diagnosing mycobacterial disease: direct detection and differentiation of Mycobacterium tuberculosis complex and non-tuberculous mycobacteria in clinical specimens using multiplex real-time PCR. J Clin Pathol 2018; 71: 774-780.

Gopinath K, Singh S. Multiplex PCR assay for simultaneous detection and differentiation of Mycobacterium tuberculosis, Mycobacterium avium complexes and other mycobacterial species directly from clinical specimens. $J$ Appl Microbiol 2009; 107: 425-435.

Shibata Y, Horita N, Yamamoto M, et al. Diagnostic test accuracy of anti-glycopeptidolipid-core IgA antibodies for Mycobacterium avium complex pulmonary disease: systematic review and meta-analysis. Sci Rep 2016; 6: 29325.

Ferroni A, Sermet-Gaudelus I, Le Bourgeois M, et al. Measurement of immunoglobulin G against mycobacterial antigen A60 in patients with cystic fibrosis and lung infection due to Mycobacterium abscessus. Clin Infect Dis 2005; 40: 58-66.

Qvist T, Pressler T, Taylor-Robinson D, et al. Serodiagnosis of Mycobacterium abscessus complex infection in cystic fibrosis. Eur Respir J 2015; 46: 707-716.

Clinical, Laboratory Standards Institute. Susceptibility Testing of Mycobateria, Nocardiae, and Other Aerobic Actinomyctes; Approved Standard. 2nd Edn. CLSI document M24-A2. Wayne, Clinical and Laboratory Standards Institute, 2011.

Wallace RJ, Brown BA, Griffith DE, et al. Clarithromycin regimens for pulmonary Mycobacterium avium complex. The first 50 patients. Am J Respir Crit Care Med 1996; 153: 1766-1772.

Tanaka E, Kimoto T, Tsuyuguchi K, et al. Effect of clarithromycin regimen for Mycobacterium avium complex pulmonary disease. Am J Respir Crit Care Med 1999; 160: 866-872.

Brown-Elliott BA, Iakhiaeva E, Griffith DE, et al. In vitro activity of amikacin against isolates of Mycobacterium avium complex with proposed MIC breakpoints and finding of a 16S rRNA gene mutation in treated isolates. J Clin Microbiol 2013; 51: 3389-3394.

Griffith DE, Eagle G, Thomson R, et al. Amikacin Liposome Inhalation Suspension for Treatment-Refractory Lung Disease Caused by Mycobacterium avium Complex (CONVERT): a prospective, open-label, randomized study. Am J Respir Crit Care Med 2018; in press [https://doi.org/10.1164/rccm.201807-1318OC].

van Ingen J, Kuijper EJ. Drug susceptibility testing of nontuberculous mycobacteria. Future Microbiol 2014; 9: 1095-1110.

Koh W-J, Jeon K, Lee NY, et al. Clinical significance of differentiation of Mycobacterium massiliense from Mycobacterium abscessus. Am J Respir Crit Care Med 2011; 183: 405-410.

Harada T, Akiyama Y, Kurashima A, et al. Clinical and microbiological differences between Mycobacterium abscessus and Mycobacterium massiliense lung diseases. J Clin Microbiol 2012; 50: 3556-3561.

Olivier KN, Griffith DE, Eagle G, et al. Randomized trial of liposomal amikacin for inhalation in nontuberculous mycobacterial lung disease. Am J Respir Crit Care Med 2017; 195: 814-823.

Ferro BE, Srivastava S, Deshpande D, et al. Tigecycline is highly efficacious against Mycobacterium abscessus pulmonary disease. Antimicrob Agents Chemother 2016; 60: 2895-2900.

Ferro BE, Srivastava S, Deshpande D, et al. Failure of the amikacin, cefoxitin, and clarithromycin combination regimen for treating pulmonary Mycobacterium abscessus infection. Antimicrob Agents Chemother 2016; 60: 6374-6376.

Richard J, Wallace J, Dunbar D, et al. Rifampin-resistant Mycobacterium kansasii. Clin Infect Dis 1994; 18: 736-743.

Hwang JA, Kim S, Jo K-W, et al. Natural history of Mycobacterium avium complex lung disease in untreated patients with stable course. Eur Respir J 2017; 49: 1600537.

Lee G, Lee KS, Moon JW, et al. Nodular bronchiectatic Mycobacterium avium complex pulmonary disease. Natural course on serial computed tomographic scans. Ann Am Thorac Soc 2013; 10: 299-306.

1 Gochi M, Takayanagi N, Kanauchi T, et al. Retrospective study of the predictors of mortality and radiographic deterioration in 782 patients with nodular/bronchiectatic Mycobacterium avium complex lung disease. BMJ Open 2015; 5: e008058.

2 Park J, Cho J, Lee C-H, et al. Progression and treatment outcomes of lung disease caused by Mycobacterium abscessus and Mycobacterium massiliense. Clin Infect Dis 2017; 64: 301-308.

Hayashi M, Takayanagi N, Kanauchi T, et al. Prognostic factors of $634 \mathrm{HIV}$-negative patients with Mycobacterium avium complex lung disease. Am J Respir Crit Care Med 2012; 185: 575-583.

Novosad SA, Henkle E, Schafer S, et al. Mortality after respiratory isolation of nontuberculous mycobacteria: a comparison of patients who did and did not meet disease criteria. Ann Am Thorac Soc 2017; 14: 1112-1119.

Zoumot Z, Boutou AK, Gill SS, et al. Mycobacterium avium complex infection in non-cystic fibrosis bronchiectasis. Respirology 2014; 19: 714-722.

6 Andréjak C, Thomsen VØ, Johansen IS, et al. Nontuberculous pulmonary mycobacteriosis in Denmark: incidence and prognostic factors. Am J Respir Crit Care Med 2010; 181: 514-521.

7 Marras TK, Campitelli MA, Lu H, et al. Pulmonary nontuberculous mycobacteria-associated deaths, Ontario, Canada, 2001-2013. Emerging Infect Dis 2017; 23: 468-476. 
158 Kumagai S, Ito A, Hashimoto $\mathrm{T}$, et al. Development and validation of a prognostic scoring model for Mycobacterium avium complex lung disease: an observational cohort study. BMC Infect Dis 2017; 17: 436.

Shu C-C, Lee C-H, Hsu C-L, et al. Clinical characteristics and prognosis of nontuberculous mycobacterial lung disease with different radiographic patterns. Lung 2011; 189: 467-474.

160 Fleshner M, Olivier KN, Shaw PA, et al. Mortality among patients with pulmonary non-tuberculous mycobacteria disease. Int J Tuberc Lung Dis 2016; 20: 582-587.

161 Haworth CS, Banks J, Capstick T, et al. British Thoracic Society guidelines for the management of non-tuberculous mycobacterial pulmonary disease (NTM-PD). Thorax 2017; 72: ii1-ii64.

162 Schoenfeld N, Haas W, Richter E, et al. Recommendations of the German Central Committee against Tuberculosis (DZK) and the German Respiratory Society (DGP) for the diagnosis and treatment of non-tuberculous mycobacterioses. Pneumologie 2016; 70: 250-276.

163 Nontuberculous Mycobacteriosis Control Committee of the Japanese Society for Tuberculosis, Scientific Assembly for Infection and Tuberculosis of the Japanese Respiratory Society. Guidelines for chemotherapy of pulmonary nontuberculous mycobacterial disease-2012 revised version. Kekkaku 2013; 88: 29-32.

164 Wallace RJ, Brown-Elliott BA, McNulty S, et al. Macrolide/azalide therapy for nodular/bronchiectatic mycobacterium avium complex lung disease. Chest 2014; 146: 276-282.

165 Kwak N, Park J, Kim E, et al. Treatment outcomes of Mycobacterium avium complex lung disease: a systematic review and meta-analysis. Clin Infect Dis 2017; 65: 1077-1084.

166 Loebinger MR. Mycobacterium avium complex infection: phenotypes and outcomes. Eur Respir J 2017; 50: 1701380 .

167 Morimoto K, Namkoong H, Hasegawa N, et al. Macrolide-resistant Mycobacterium avium complex lung disease: analysis of 102 consecutive cases. Ann Am Thorac Soc 2016; 13: 1904-1911.

168 Griffith DE, Brown-Elliott BA, Langsjoen B, et al. Clinical and molecular analysis of macrolide resistance in Mycobacterium avium complex lung disease. Am J Respir Crit Care Med 2006; 174: 928-934.

169 Jo K-W, Kim S, Lee JY, et al. Treatment outcomes of refractory MAC pulmonary disease treated with drugs with unclear efficacy. J Infect Chemother 2014; 20: 602-606.

170 Lyu J, Jang HJ, Song JW, et al. Outcomes in patients with Mycobacterium abscessus pulmonary disease treated with long-term injectable drugs. Respir Med 2011; 105: 781-787.

171 Jarand J, Levin A, Zhang L, et al. Clinical and microbiologic outcomes in patients receiving treatment for Mycobacterium abscessus pulmonary disease. Clin Infect Dis 2011; 52: 565-571.

172 Pasipanodya JG, Ogbonna D, Ferro BE, et al. Systematic review and meta-analyses of the effect of chemotherapy on pulmonary Mycobacterium abscessus outcomes and disease recurrence. Antimicrob Agents Chemother 2017; 61: 810.

173 Lyu J, Kim B-J, Kim B-J, et al. A shorter treatment duration may be sufficient for patients with Mycobacterium massiliense lung disease than with Mycobacterium abscessus lung disease. Respir Med 2014; 108: 1706-1712.

174 Wallace RJ, Dukart G, Brown-Elliott BA, et al. Clinical experience in 52 patients with tigecycline-containing regimens for salvage treatment of Mycobacterium abscessus and Mycobacterium chelonae infections. J Antimicrob Chemother 2014; 69: 1945-1953.

175 Yang B, Jhun BW, Moon SM, et al. Clofazimine-containing regimen for the treatment of Mycobacterium abscessus lung disease. Antimicrob Agents Chemother 2017; 61: e02052-16.

176 Martiniano SL, Wagner BD, Levin A, et al. Safety and effectiveness of clofazimine for primary and refractory nontuberculous mycobacterial infection. Chest 2017; 152: 800-809.

177 Brown-Elliott BA, Crist CJ, Mann LB, et al. In vitro activity of linezolid against slowly growing nontuberculous mycobacteria. Antimicrob Agents Chemother 2003; 47: 1736-1738.

178 Wallace RJ, Brown-Elliott BA, Ward SC, et al. Activities of linezolid against rapidly growing mycobacteria. Antimicrob Agents Chemother 2001; 45: 764-767.

179 Inoue T, Tsunoda A, Nishimoto E, et al. Successful use of linezolid for refractory Mycobacterium abcessus infection: A case report. Respir Med Case Rep 2018; 23: 43-45.

180 Lee RA, Rom WN, Addrizzo-Harris DJ. The use of linezolid and nebulized amikacin in a case of Mycobacterium chelonae/Mycobacterium abscessus pulmonary disease. Chest 2010; 138: 86A.

181 Hayward B, Addrizzo-Harris D. Successful use of inhaled antibiotics for primary treatment of Mycobacterial abscessus infection. Am J Respir Crit Care Med 2016; 193: A3741.

182 Brown-Elliott BA, Wallace RJ, Blinkhorn R, et al. Successful treatment of disseminated Mycobacterium chelonae infection with linezolid. Clin Infect Dis 2001; 33: 1433-1434.

183 Nannini EC, Keating M, Binstock P, et al. Successful treatment of refractory disseminated Mycobacterium avium complex infection with the addition of linezolid and mefloquine. J Infect 2002; 44: 201-203.

184 Morales P, Ros JA, Blanes M, et al. Successful recovery after disseminated infection due to Mycobacterium abscessus in a lung transplant patient: subcutaneous nodule as first manifestation-a case report. Transplant Proc 2007; 39: 2413-2415.

185 Furuya EY, Paez A, Srinivasan A, et al. Outbreak of Mycobacterium abscessus wound infections among "lipotourists" from the United States who underwent abdominoplasty in the Dominican Republic. Clin Infect Dis 2008; 46: 1181-1188.

186 Kyle SD, Porter WM. Mycobacterium chelonae infection successfully treated with oral clarithromycin and linezolid. Br J Dermatol 2004; 151: 1101.

187 Chetchotisakd P, Anunnatsiri S. Linezolid in the treatment of disseminated nontuberculous mycobacterial infection in anti-interferon-gamma autoantibody-positive patients. Southeast Asian J Trop Med Public Health 2014; 45: 1125-1131.

188 Winthrop KL, Ku JH, Marras TK, et al. The tolerability of linezolid in the treatment of nontuberculous mycobacterial disease. Eur Respir J 2015; 45: 1177-1179.

189 Tang YW, Cheng B, Yeoh SF, et al. Tedizolid activity against clinical Mycobacterium abscessus complex isolatesan in vitro characterization study. Front Microbiol 2018; 9: 2095.

190 Compain F, Soroka D, Heym B, et al. In vitro activity of tedizolid against the Mycobacterium abscessus complex. Diagn Microbiol Infect Dis 2018; 90: 186-189. 
191 Brown-Elliott BA, Wallace RJ. In vitro susceptibility testing of tedizolid against nontuberculous mycobacteria. J Clin Microbiol 2017; 55: 1747-1754.

192 Luoma K, Singh S, Addrizzo-Harris D. Oxazolidinone therapy for recalcitrant pulmonary nontuberculous mycobacterial infection. Chest 2017; 152: A128.

193 Yuste JR, Bertó J, Del Pozo JL, et al. Prolonged use of tedizolid in a pulmonary non-tuberculous mycobacterial infection after linezolid-induced toxicity. J Antimicrob Chemother 2017; 72: 625-628.

194 Olivier KN, Shaw PA, Glaser TS, et al. Inhaled amikacin for treatment of refractory pulmonary nontuberculous mycobacterial disease. Ann Am Thorac Soc 2014; 11: 30-35.

195 Aguilar-Ayala DA, Cnockaert M, Andre E, et al. In vitro activity of bedaquiline against rapidly growing nontuberculous mycobacteria. J Med Microbiol 2017; 66: 1140-1143.

196 Pang Y, Zheng H, Tan Y, et al. In vitro activity of bedaquiline against nontuberculous mycobacteria in China. Antimicrob Agents Chemother 2017; 61: 103.

197 Brown-Elliott BA, Philley JV, Griffith DE, et al. In vitro susceptibility testing of bedaquiline against Mycobacterium avium complex. Antimicrob Agents Chemother 2017; 61: AAC.01798-16.

198 Huitric E, Verhasselt P, Andries K, et al. In vitro antimycobacterial spectrum of a diarylquinoline ATP synthase inhibitor. Antimicrob Agents Chemother 2007; 51: 4202-4204.

199 Petrella S, Cambau E, Chauffour A, et al. Genetic basis for natural and acquired resistance to the diarylquinoline R207910 in mycobacteria. Antimicrob Agents Chemother 2006; 50: 2853-2856.

200 Alexander DC, Vasireddy R, Vasireddy S, et al. Emergence of mmpT5 variants during bedaquiline treatment of Mycobacterium intracellulare lung disease. J Clin Microbiol 2017; 55: 574-584.

201 Philley JV, Wallace RJ, Benwill JL, et al. Preliminary results of bedaquiline as salvage therapy for patients with nontuberculous mycobacterial lung disease. Chest 2015; 148: 499-506.

202 Krieger D, Schönfeld N, Vesenbeckh S, et al. Is delamanid a potential agent in the treatment of diseases caused by Mycobacterium avium-intracellulare? Eur Respir J 2016; 48: 1803-1804.

203 Krieger D, Vesenbeckh S, Schönfeld N, et al. Mefloquine as a potential drug against multidrug-resistant tuberculosis. Eur Respir J 2015; 46: 1503-1505.

204 Bermudez LE, Kolonoski $\mathrm{P}$, Wu M, et al. Mefloquine is active in vitro and in vivo against Mycobacterium avium complex. Antimicrob Agents Chemother 1999; 43: 1870-1874.

205 Ramirez J, Mason C, Ali J. Use of mefloquine in multidrug-resistant Mycobacterium avium complex pulmonary disease in an HIV-negative patient. Curr Ther Res Clin Exp 2007; 68: 421-429.

206 Deshpande D, Srivastava S, Musuka S, et al. Thioridazine as chemotherapy for Mycobacterium avium complex diseases. Antimicrob Agents Chemother 2016; 60: 4652-4658.

207 Larsson L-O, Polverino E, Hoefsloot W, et al. Pulmonary disease by non-tuberculous mycobacteria - clinical management, unmet needs and future perspectives. Expert Rev Respir Med 2017; 11: 977-989.

208 Georgopapadakou NH. The wobbly status of ketolides: where do we stand? Expert Opin Investig Drugs 2014; 23: 1313-1319.

209 Low JL, Wu M-L, Aziz DB, et al. Screening of TB actives for activity against nontuberculous mycobacteria delivers high hit rates. Front Microbiol 2017; 8: 1539.

210 Li W, Yazidi A, Pandya AN, et al. MmpL3 as a target for the treatment of drug-resistant nontuberculous mycobacterial infections. Front Microbiol 2018; 9: 1547.

211 De Groote MA, Jackson M, Gonzalez-Juarrero M, et al. Optimization and lead selection of benzothiazole amide analogs toward a novel antimycobacterial agent. Front Microbiol 2018; 9: 2231.

212 Dupont C, Viljoen A, Dubar F, et al. A new piperidinol derivative targeting mycolic acid transport in Mycobacterium abscessus. Mol Microbiol 2016; 101: 515-529.

213 Lefebvre A-L, Dubée V, Cortes M, et al. Bactericidal and intracellular activity of $\beta$-lactams against Mycobacterium abscessus. J Antimicrob Chemother 2016; 71: 1556-1563.

214 Le Run E, Arthur M, Mainardi J-L. In vitro and intracellular activity of imipenem combined with rifabutin and avibactam against Mycobacterium abscessus. Antimicrob Agents Chemother 2018; 62: 1587.

215 Kaushik A, Gupta C, Fisher S, et al. Combinations of avibactam and carbapenems exhibit enhanced potencies against drug-resistant Mycobacterium abscessus. Future Microbiol 2017; 12: 473-480.

216 Deshpande D, Srivastava S, Chapagain ML, et al. The discovery of ceftazidime/avibactam as an anti-Mycobacterium avium agent. J Antimicrob Chemother 2017; 72: i36-i42.

217 Jenkins PA, Campbell IA, Banks J, et al. Clarithromycin vs ciprofloxacin as adjuncts to rifampicin and ethambutol in treating opportunist mycobacterial lung diseases and an assessment of Mycobacterium vaccae immunotherapy. Thorax 2008; 63: 627-634.

218 Squires KE, Murphy WF, Madoff LC, et al. Interferon-gamma and Mycobacterium avium-intracellulare infection. J Infect Dis 1989; 159: 599-600.

219 Squires KE, Brown ST, Armstrong D, et al. Interferon-gamma treatment for Mycobacterium avium-intracellulare complex bacillemia in patients with AIDS. J Infect Dis 1992; 166: 686-687.

220 Holland SM, Eisenstein EM, Kuhns DB, et al. Treatment of refractory disseminated nontuberculous mycobacterial infection with interferon gamma. A preliminary report. N Engl J Med 1994; 330: 1348-1355.

221 Hallstrand TS, Ochs HD, Zhu Q, et al. Inhaled IFN-gamma for persistent nontuberculous mycobacterial pulmonary disease due to functional IFN-gamma deficiency. Eur Respir J 2004; 24: 367-370.

222 Chatte G, Panteix G, Perrin-Fayolle M, et al. Aerosolized interferon gamma for Mycobacterium avium-complex lung disease. Am J Respir Crit Care Med 1995; 152: 1094-1096.

223 Lam PK, Griffith DE, Aksamit TR, et al. Factors related to response to intermittent treatment of Mycobacterium avium complex lung disease. Am J Respir Crit Care Med 2006; 173: 1283-1289.

224 Milanes-Virelles MT, Garcia-Garcia I, Santos-Herrera Y, et al. Adjuvant interferon gamma in patients with pulmonary atypical mycobacteriosis: a randomized, double-blind, placebo-controlled study. BMC Infect Dis 2008; 8: 17.

225 Moser C, Jensen PO, Pressler T, et al. Adjunctive treatment with granulocyte-macrophage colony stimulating factor (GM-CSF) of CF patients with severe Mycobacterium abscessus lung infection. Pediatr Pulmonol 2005; 40: 272 . 
226 Scott JP, Ji Y, Kannan M, et al. Inhaled granulocyte-macrophage colony-stimulating factor for Mycobacterium abscessus in cystic fibrosis. Eur Respir J 2018; 51: 1702127.

227 Jamaati H, Mortaz E, Pajouhi Z, et al. Nitric oxide in the pathogenesis and treatment of tuberculosis. Front Microbiol 2017; 8: 2008.

228 Yaacoby-Bianu K, Gur M, Toukan Y, et al. compassionate nitric oxide adjuvant treatment of persistent Mycobacterium infection in cystic fibrosis patients. Pediatr Infect Dis J 2018; 37: 336-338.

229 Gori A, Franzetti F, Marchetti G, et al. Clinical and immunological improvement in a patient who received thalidomide treatment for refractory Mycobacterium avium complex infection. Clin Infect Dis 1998; 26: 184-185. 